\title{
Noticias falsas y desinformación sobre el Covid-19: análisis comparativo de seis países iberoamericanos
}

\author{
Fake news about Covid-19: a comparative analysis of six \\ Iberoamerican countries
}

\author{
Liliana María Gutiérrez-Coba. Universidad de La Sabana. Colombia. \\ lilianagc@unisabana.edu.co \\ $[\mathrm{CV}]$ (1) $\mathrm{R}$ \\ Patricia Coba-Gutiérrez. Universidad de Ibagué. Colombia.
}

patricia.coba@unibague.edu.co

[CV] (1) G R

Javier Andrés Gómez-Díaz. Corporación Universitaria Minuto de Dios, UNIMINUTO.

Colombia.javier.gomezd@uniminuto.edu

$[\mathrm{CV}]$ (1) $\mathrm{R}^{\mathrm{C}}$

Cómo citar este artículo / Referencia normalizada

Gutiérrez-Coba, L. M., Coba-Gutiérrez, P. \& Gómez-Díaz, J. A. (2020). Noticias falsas y desinformación sobre el Covid-19: análisis comparativo de seis países iberoamericanos. Revista Latina de Comunicación Social, 78, 237-264. https://www.doi.org/10.4185/RLCS-2020-1476

\begin{abstract}
RESUMEN
Introducción: Los productores de desinformación y noticias falsas encuentran en el temor, la incertidumbre en tiempos de pandemia y las redes sociales virtuales facilitadores para su difusión, haciendo más difícil su detección para expertos y legos en el tema. Las tipologías diseñadas para la identificación y clasificación de bulos permiten su análisis desde perspectivas teóricas como las cámaras de eco, las burbujas de filtro, la manipulación de la información y la disonancia cognitiva. Método: Se realizó un análisis de contenido a 371 noticias falsas, previamente verificadas por factcheckers. Luego de una prueba de intercodificadores, se procedió a clasificar los bulos según su tipo, intencionalidad, tema principal abordado, las redes en que circularon, la técnica de engaño, el país de origen, su carácter transnacional, entre otras variables. Resultados: La intención de bulo más común fue de carácter ideológico, asociada con temas como los falsos anuncios de gobiernos, organizaciones o personajes públicos, así como con la técnica de contexto falso para su elaboración. Una cuarta parte de los bulos analizados se repitieron en varios países, promoviendo principalmente falsas curas con contenidos fabricados como técnica de engaño. Discusión y Conclusiones: Desinformar es un fenómeno de manipulación y filtraje basado en la coincidencia ideológica y emocional que comparten quienes circulan bulos. La (des)información que converge con los intereses de sus usuarios, hace que su difusión se haga de manera indiscriminada y facilite su transnacionalidad, con leves modificaciones, sin que esto afecte su aceptación y su recirculación.
\end{abstract}

PALABRAS CLAVE: Noticias falsas, Covid-19, intencionalidad, técnicas de engaño, transnacionalidad, Iberoamérica, análisis de contenido. 


\begin{abstract}
Introduction: Producers of misinformation and fake news find in fear, uncertainty in pandemic times, and in virtual social networks facilitators for disseminating them, doing harder the task to detect them even for experts and laymen. Typologies designed to identify and classify hoaxes allow their analysis from theoretical perspectives such as echo chambers, filter bubbles, information manipulation, and cognitive dissonance. Method: A content analysis was developed with 371 fake news, previously verified by fact-checkers. After intercoders test, it was proceeded to classify disinformation according to their type, intentionality, main topic addressed, networks where they circulated, deception technique, country of origin, transnational character, among other variables.

Results: The most common intent of fake news was ideological, associated with issues such as false announcements by governments, organizations, or public figures, as well as with false context elaboration technique. A quarter of the hoaxes analyzed were repeated in several countries, mainly promoting false cures with fabricated content as a deception technique. Discussion and Conclusions: Disinformation is a manipulation and filtering phenomenon based on ideological and emotional coincidence shared by those who circulate them. (Dis)information that converges with the users' interests, makes its dissemination indiscriminate and facilitates its transnationality, with slight modifications, without affecting its acceptance and recirculation.
\end{abstract}

KEYWORDS: Fake news, Covid-19, Intentionality, Deception techniques, Transnationality, Iberoameric, Content Analysis.

\title{
1. Introducción
}

El concepto de Fake news o noticias falsas ha sido tratado por diversos autores, sin embargo, no existe una definición universal del término. Algunos investigadores distinguen entre los términos disinformation: noticias creadas con la intención de engañar, y misinformation: noticias elaboradas sin la intención de engañar, pero que terminan desinformando (Allcott \& Gentzkow, 2017; Fallis, 2015; Giglietto et al., 2019). Otros como Lazer et al., (2018) señalan que se trata de información fabricada que imita el contenido de los medios de comunicación y Tandoc et al., (2018) las describe como publicaciones virales de cuentas ficticias, fabricadas para parecer noticias.

El análisis de lo que diversos autores han llegado a definir como noticias falsas, lleva consecuentemente a la propuesta de tipologías que involucran una serie de categorías que van desde la sátira y la parodia basada en noticias, hasta la propaganda, la información manipulada y la información fabricada, e incluso, la información mal reporteada por los periodistas, por mencionar algunas (Tandoc et al., 2018; Wardle, 2017a). Para Farkas \& Schou, (2018) implica también un enfoque continuo en la intencionalidad detrás de la producción y circulación de noticias falsas que, en concepto de (Allcott \& Gentzkow, 2017), están principalmente motivadas por intereses financieros e ideológicos. Los primeros porque, al ser escandalosas y viralizarse, las noticias falsas producen clics que se transforman en ganancias por publicidad, y los segundos, porque las noticias falsas pueden promover ideas que favorecen a ciertas personas y desacreditan o desfavorecen a otras. Con todo, ni el asunto de las tipologías ni el de las intenciones detrás de la producción de noticias falsas están aún resueltos y es precisamente por ello que es importante estudiarlos.

El fenómeno de la diseminación de rumores e información sin confirmar, así como de las noticias falsas (bulos) ha tenido diferentes efectos e intenciones a través del tiempo. La idea de que la opinión pública responde a la mentira, apelando a la emotividad, aun cuando se les suministre hechos verificables que la refuten, fue tratada por Parménides de Elea, (s/f) y por Platón (2003) siglos atrás. Berkowitz \& Schwartz (2016) señalan la existencia de bulos y sátiras desde el siglo XVIII, y precisan que las noticias falsas comenzaron a surgir en el siglo XIX en un momento de rápido 
crecimiento para los periódicos ayudado por las tecnologías emergentes, tal y como sucede actualmente. De la misma forma, la diseminación de rumores y desinformación ha sido una práctica utilizada en épocas de conflicto como arma desmoralizante de los adversarios o tranquilizante para los miembros del propio bando (Burkhardt, 2017). El poder de las noticias falsas para generar pánico y terror suele relacionarse también con la malinterpretación que se hizo en 1938 de la transmisión radial de la novela de Orson Wells 'La guerra de los mundos', que convenció a la audiencia de que Norteamérica estaba siendo invadida por extraterrestres (Tandoc et al., 2018).

Anteriormente los rumores y noticias falsas tardaban más en propagarse y, por lo general, su difusión se replegaba solo contexto local en que se originaban, a menos que se tratase de información con características especialmente graves. Actualmente, la inmediatez y la inexistencia de fronteras geográficas para la difusión de la información a través de la internet y las redes sociales o de aplicaciones de mensajería, hace que sea más difícil identificar y clasificar noticias falsas o detectar su origen e intencionalidad con precisión. Como revelan Vosoughi et al., (2018), las noticias falsas se difunden más rápido, más lejos y más profundamente que las verdaderas y tienen un probabilidad superior al $70 \%$ para ser compartidas.

En el centro del debate está la interacción social-virtual, ya que el componente emocional juega un papel importante al momento de compartir información por redes sociales o aplicaciones de mensajería como WhatsApp (Tanz, 2017). El Pew Research Institute (Mitchell et al., 2017) señala que las noticias provenientes de correos y mensajes de texto, entre amigos o familiares, provoca una mayor actividad (compartir, buscar información adicional o hablar del contenido On/Offline). Paralelamente, ocurre con el aumento del tribalismo, es decir, la tendencia a identificarse con grupos de personas que comparten ideas similares con las que el usuario de estas redes refuerza sus creencias (Rainie et al., 2017).

Entre los factores que facilitan la propagación de las noticias falsas está el efecto desinhibidor de la interacción en línea, particularmente cuando se usan perfiles falsos que mantienen el anonimato, posibilitando la publicación de supuestos datos para desacreditar acciones, personas u organizaciones.

Rehm (2018) destaca también que hay cierto tipo de contenidos que son más propensos a viralizarse, porque son agresivos, sensibilizantes, provocativos, verosímiles y porque la postura del artículo se identifica con facilidad. Sin embargo, aun cuando se puedan identificar los factores que favorecen la distribución de las noticias falsas, Wardle (2017) alerta sobre la complejidad del problema dado que, el término falso no logra describir la diferencia ente información errónea (Misinformation) como el acto compartir inadvertidamente información falsa, y desinformación: crear y difundir información falsa deliberadamente.

Este fenómeno adquiere más relevancia si se tiene en cuenta que en el contexto Iberoamericano, cada vez más personas tienen a las redes sociales como su principal medio de consumo de noticias. Según el Digital News Report España (Vara Miguel et al., 2020) "uno de cada tres internautas de 18 a 34 años utiliza redes sociales y blogs como fuente preferida de noticias (31\%). Uno de cada cuatro (25\%) entre los de 18 a 44, mientras solo uno de cada diez (10\%) entre los internautas mayores de 45 años elige las redes sociales y blogs como medio favorito para informarse" (párrafo 15). Igualmente, el Digital News Report (Newman, 2017) advierte que los latinoamericanos son los mayores consumidores de noticias a través de redes sociales y de aplicaciones de chat en el mundo.

El problema de las noticias falsas adquiere entonces dimensiones importantes, dado que ciertas personas podrían estar siendo sistemáticamente desinformadas, más aún si se tiene en cuenta el 
diseño que han hecho las empresas tecnológicas de algoritmos que sólo ofrecen a la gente contenidos que refuerzan su propia línea ideológica, como propone la Teoría de la Burbuja de Filtro (Pariser, 2011) que refiere a la manera como Google, Facebook y otras páginas están programadas para recoger información sobre los intereses, hábitos y preferencias de la gente y conseguir que se filtre aquello en lo que las personas no han mostrado interés. Esta programación informática permite entender que la información falsa que muchos usuarios comparten, de una u otra manera está en sintonía con sus gustos, ideologías y sentires.

Además, las redes sociales reproducen comunidades de 'lo igual', es decir que el mundo digital se reduce a datos numéricos y provee al usuario información similar a lo que suele consumir, excluyendo la información que no concuerda con sus gustos y preferencias (Han, 2016). Ello sobreexpone las opiniones de conformidad de los usuarios de redes sociales digitales y hace que elijan información que se alinea con sus ideologías, como lo propone la Teoría de las Cámaras de Eco (Cardenal et al., 2019; Munson \& Resnick, 2010).

La Teoría de la Manipulación de la Información (McCornack et al., 2014) también permite el abordaje de las noticias falsas o bulos como una forma de fabricar desinformación que se produce intencionalmente de manera artificial y que, si bien se puede basar en situaciones o experiencias reales, difiere en contenido y calidad la información verdadera.

Un agravante de esta situación es que las personas tienen dificultades para reconocer qué información es verdadera y cuál no lo es, porque usualmente los bulos se originan en sitios web diseñados para desinformar, cuyos nombres tienden a parecerse a organizaciones de noticias legítimas; otros vienen de sitios dedicados a hacer contenido satírico y otros de sitios con inclinación partidista (Allcott \& Gentzkow, 2017).

Por otra parte, Pennycook et al., (2018) afirman que es más fácil que las personas crean algo si lo han escuchado antes, ya que los seres humanos utilizan la familiaridad como un atajo mental para evaluar la precisión de la información. Aún si lo que se informa es falso, haberlo leído repetidas veces aumenta la posibilidad de considerarlo como verdadero, efectos que estos investigadores han denominado 'verdad ilusoria'. La Teoría de la Disonancia Cognitiva explica además que las personas tienden a clasificar como falsa y a rechazar aquellas noticias que son contrarias a sus creencias, como una forma de reducir la incomodidad que les genera el conflicto que surge entre la (des)información y sus valores, incluso cuando las noticias son ciertas (Festinger, 1957; Sindermann et al., 2020).

\subsection{Desinformación en tiempo de pandemia}

La pandemia de coronavirus ha sido un escenario propicio para la creación y propagación de noticias falsas. Tal como señala el Digital News Report (2020) que anualmente publica los resultados de una encuesta en 40 países de los seis continentes (2000 personas por país), y que en esta ocasión hizo consultas adicionales durante abril en Reino Unido, Estados Unidos, Alemania, España, Corea del Sur y Argentina, a raíz de esta crisis sanitaria el uso de redes sociales y en línea aumentó sustancialmente en la mayoría de los países:

En abril, descubrimos que, en nuestros seis países encuestados, casi una cuarta parte (24\%) usó WhatsApp para encontrar, discutir o compartir noticias sobre COVID-19, siete puntos más en promedio que en nuestra encuesta de enero que preguntó sobre el uso de cualquier noticia. Alrededor de un quinto (18\%) se unió a un grupo de apoyo o discusión con personas que no conocían en Facebook o WhatsApp específicamente para hablar sobre COVID-19 y la mitad $(51 \%)$ participó en grupos con colegas, amigos o familiares (p. 14). 
Aún antes de la pandemia, más de la mitad de los encuestados decían no reconocer fácilmente la información verdadera de la falsa en las redes sociales y, aunque el informe también señala que se incrementó parcialmente el consumo de medios tradicionales a raíz de la pandemia, sigue siendo preocupante que la desinformación tenga la posibilidad de llegar a la ciudadanía a través de las redes sociales On/Offline.

Entre enero y marzo de 2020, el Reuters Institute (Newman, s. f.) realizó una investigación para establecer los tipos y fuentes de desinformación sobre Covid-19 que circularon en inglés en ese periodo. Cuando se publicaron los resultados en abril, los investigadores alertaron acerca de que más del $20 \%$ de los 225 bulos analizados seguían circulando en Facebook y Youtube, y más del 55\% lo hacían en Twitter, pese a que habían sido chequeados por organizaciones de verificación (Brennen et al., 2020).

El riesgo de las noticias falsas es que generan desinformación en la sociedad e, independientemente de las intenciones detrás de quienes las elaboran y distribuyen, el principal daño es que deslegitiman a las fuentes verdaderas (Baron \& Crootof, 2017), lo que en el caso de la pandemia de Covid-19 puede resultar aún más riesgoso, por las consecuencias que puede traer para la salud de las personas.

El presente estudio se centró en cinco países latinoamericanos y uno europeo. Esta diversidad se constituye en uno de los factores diferenciadores en relación con otras investigaciones realizadas (ver Brennen et al., 2020; Salaverría et al., 2020) y se analizaron los temas recurrentes, la relación entre el tipo de noticias falsas y la técnica de engaño que emplean sus creadores y la descripción de sus posibles intencionalidades. Igualmente, se efectuó una comparación de las noticias falsas que circularon por varios de los países estudiados, con el fin de establecer posibles elementos que favorecen su carácter transnacional. Todas estas cuestiones fueron el punto de partida de la investigación.

\section{Objetivos}

El objetivo principal de esta investigación es caracterizar las noticias falsas que se difundieron en seis países de Iberoamérica y hallar elementos de comparación que permitan establecer intencionalidades compartidas, especialmente entre aquellas desinformaciones que se repiten en varios países.

Derivado de lo anterior, se desprenden los siguientes objetivos específicos:

1. Comparar las características de las informaciones falsas sobre la pandemia de Covid-19 que circularon por los distintos países de analizados.

2. Determinar la relación entre el tipo de noticias falsas y la técnica de engaño a la que recurren sus creadores.

3. Describir posibles intenciones detrás de la creación de bulos sobre la pandemia y su relación con los temas sobre los que versó.

4. Identificar qué bulos se difundieron simultáneamente en los países analizados y qué elementos podrían asociarse con su carácter trasnacional. 


\section{Metodología}

\subsection{Muestra y tipo de estudio}

Para atender los objetivos y responder las preguntas de esta investigación, se diseñó un estudio bibliométrico retrospectivo (Montero, 2005) a 371 noticias falsas de España (127), Colombia (78), Bolivia (27), Perú (28), Ecuador (65) y Argentina (49), que fueron recopiladas por los portales de verificación Bolivia Verifica, Maldita.es, Newtral.es, La Silla Vacía, ColombiaCheck, Ecuador Chequea, Chequeado, Ojo Público y larepublica.pe, y que circularon durante el periodo comprendido entre el 15 de marzo y el 31 de mayo de 2020.

\subsection{Instrumento}

Para la recolección de datos se usó una plantilla que incluyó 16 variables para clasificar las noticias según el país de origen, la fecha de publicación, organización que verifica y reporta el bulo, el tema abordado, el ámbito de cobertura, el formato en que se produjo originalmente la falsa noticia, las redes sociales por las que circuló, el tipo de bulo, la técnica de engaño utilizada, la intencionalidad de la misma, la fuente a la que se atribuye la noticia, si el bulo fue reproducido (o no) en medios tradicionales de comunicación (televisión, radio o prensa), y si tiene carácter transnacional por haber circulado en diversos países (Ver Anexo 1).

Para la elaboración del instrumento se tuvo en cuenta la propuesta de Wardle, (2017), quien plantea siete tipos de información falsa: Sátira o parodia, Contenido engañoso, Contenido impostor, Contenido fabricado, Conexión falsa, Contenido falso y Contenido manipulado. Dado que Salaverría et al., (2020) señalan que algunas de estas tipologías corresponden más a técnicas de desinformación, se optó por abrir esta categoría adicional. En variables como el formato, la red social por la que circuló, la fuente y el ámbito, se tuvieron en cuenta las propuestas de Salaverría et al., (2020), mientras que las variables Intencionalidad y Carácter transnacional fueron de creación propia, como se describe a continuación.

Para el presente estudio, la variable Intencionalidad se operacionaliza en cuatro categorías: La primera de ellas es Interés ideológico, que corresponde a bulos que buscan (des)acreditar gobiernos o introducir debates anti o prosistema, asociados tanto a la postura política de quienes los producen como de quienes son cuestionados. Este es el caso de un concejal ecuatoriano quien publicó un bulo en el que usa imágenes sobre la construcción de carreteras para darle mayor fuerza a su desinformación, involucrando la gestión del mandatario nacional, como una forma de cuestionamiento ideológico (ver figura 1). 
RLCS, Revista Latina de Comunicación Social, 78, 237-264

[Investigación] DOI: 10.4185/RLCS-2020-1476| ISSN 1138-5820| Año 2020
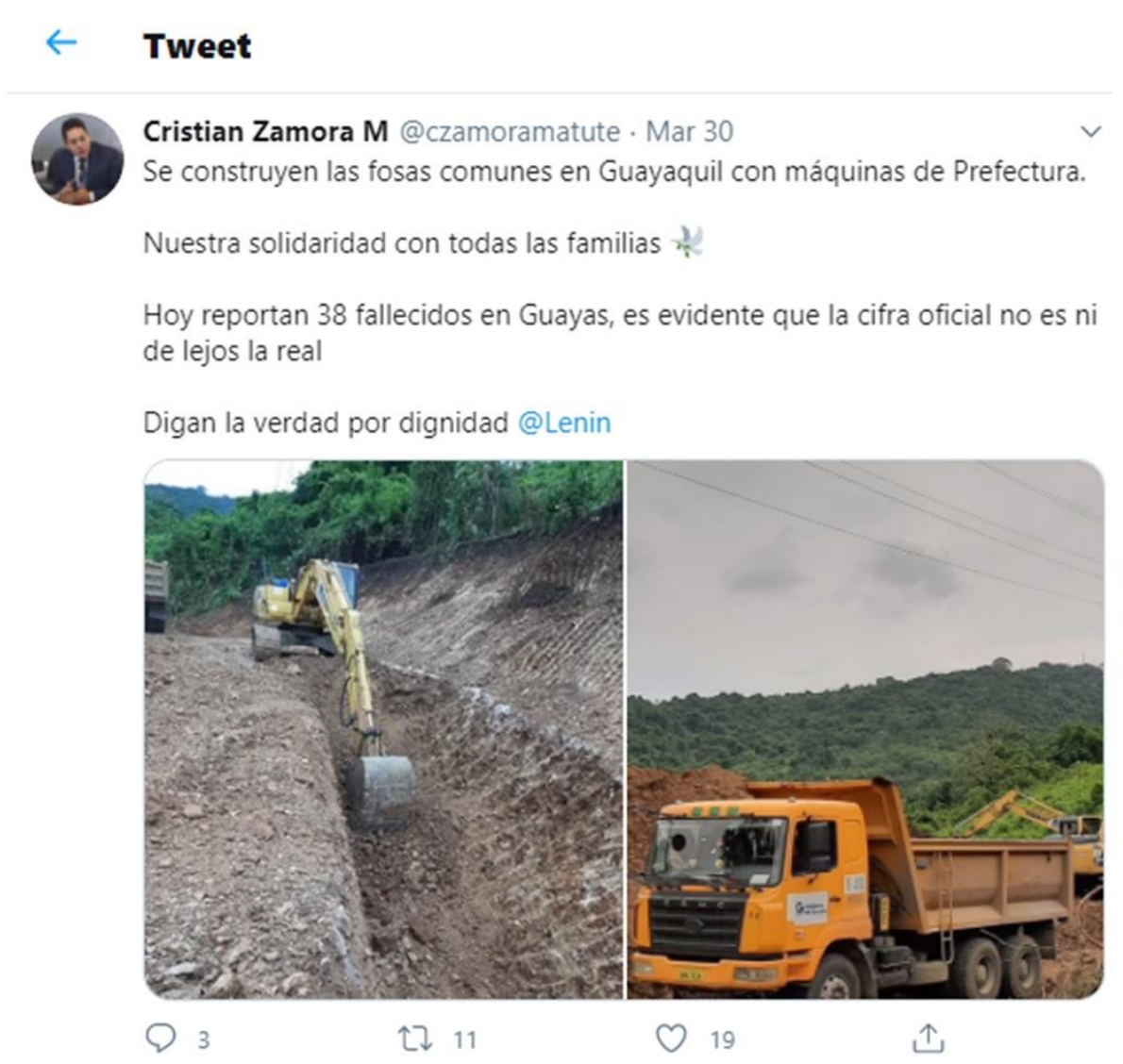

Figura 1: Bulo de interés ideológico. Involucrar cuestiones políticas en el tweet.

Fuente: @czamoramatute (Cuenta de Twitter).

La segunda categoría es Acciones delictivas, que recoge noticias falsas que, mediante tácticas persuasivas, pretenden acceder a información financiera privada o prometen supuestos réditos a corto plazo con 'mínimas inversiones' para robar a las personas. Se ejemplifica el caso de un supuesto apoyo gubernamental durante la pandemia en el que se busca embaucar incautos que, con USD250 harían parte de un sistema de ingresos "con Resultados GARANTIZADOS” (ver figura 2). 


\title{
ESTADO ALERTA: ¿Cómo Generar Ingresos desde casa mientras dure el Estado de
} Alerta por Coronavirus? Lenín Moreno ofrece Soluciones

\author{
8. lerónimo Moya Follow \\ Sep $4 \cdot 8 \mathrm{~min}$ read
}

Los ciudadanos de Ecuador no deben de arruinarse por el CODVID-19, deben de generar ingresos desde sus casas gracias a este sistema Bitcoin Code que ofrece Lenín Moreno. Solo se necesitan \$250 dólares para iniciar el sistema, con Resultados GARANTIZADOS..

Figura 2: Bulo con intención delictiva. Invita a hacer 'inversiones' en tiempos de pandemia.

Fuente: Medium.com (cuenta de blog @jeronimomoyaj).

También están los bulos con intención de desestabilizar o generar pánico, en los que se pretende desequilibrar y/o producir incertidumbre en la audiencia dejando mensajes desesperanzadores sobre el comportamiento humano. Es el ejemplo de la supuesta manipulación genética con que se creó el virus SARS-COV-2, en colaboración entre médicos norteamericanos y chinos (ver figura 3). 
RLCS, Revista Latina de Comunicación Social, 78, 237-264

[Investigación] DOI: 10.4185/RLCS-2020-1476| ISSN 1138-5820| Año 2020

Yupe al frente noticias y muladas

23 de junio a las 12:23 - a

\begin{abstract}
Finalmente, el FBI arrestó a un profesor de la Universidad de Boston que estaba en conexión con la universidad China y el laboratorio de investigación en Wuhan, y fue altamente pagado...

Ahora está muy cerca de estar claro que el Coronavirus es un bio ataque planeado y conducido por China.

-Un experto chino asegura a todos que la inhalación de vapor de agua

caliente mata el virus Corona al cien por ciento.

Incluso si el virus entró por la nariz, la garganta o los pulmones.

EI COVID-19 no puede soportar el vapor de agua caliente.

Circula está información a todos los miembros de tu familia y amigos.
\end{abstract}
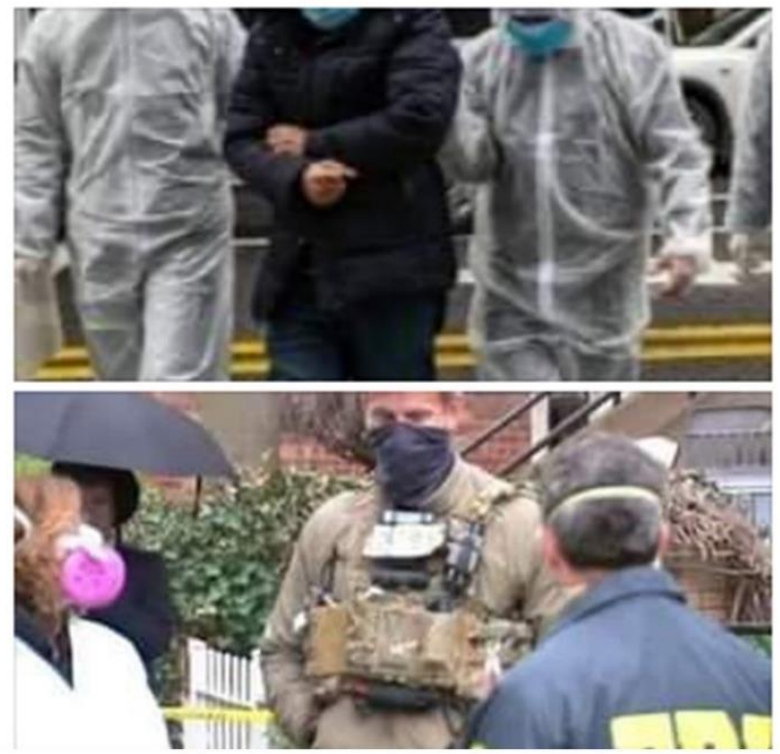

Figura 3: Bulo con intención de desestabilizar. Además de desinformar sobre la supuesta 'creación' del virus Covid-19 en un laboratorio, ofrece falsas curas milagrosas.

Fuente: https://m.facebook.com/pg/Yupe-al-frente-noticias-y-muladas (cuenta de Facebook).

Cuando el bulo no puede ser clasificado en los criterios anteriores, pero se ha compartido ampliamente, se considera que la intención que hay detrás es la de generar una alta actividad en redes sociales denominada Clickbait con la que se obtiene credibilidad, seguidores y, eventualmente, dinero por la 'viralidad' con que se movieron tales redes de (des)información. A diferencia de las anteriores categorías, pueden brindar esperanza en tiempos de incertidumbre, o supuestas 'curas milagrosas' (Ver figura 4). 


\section{LaNoticia24@}

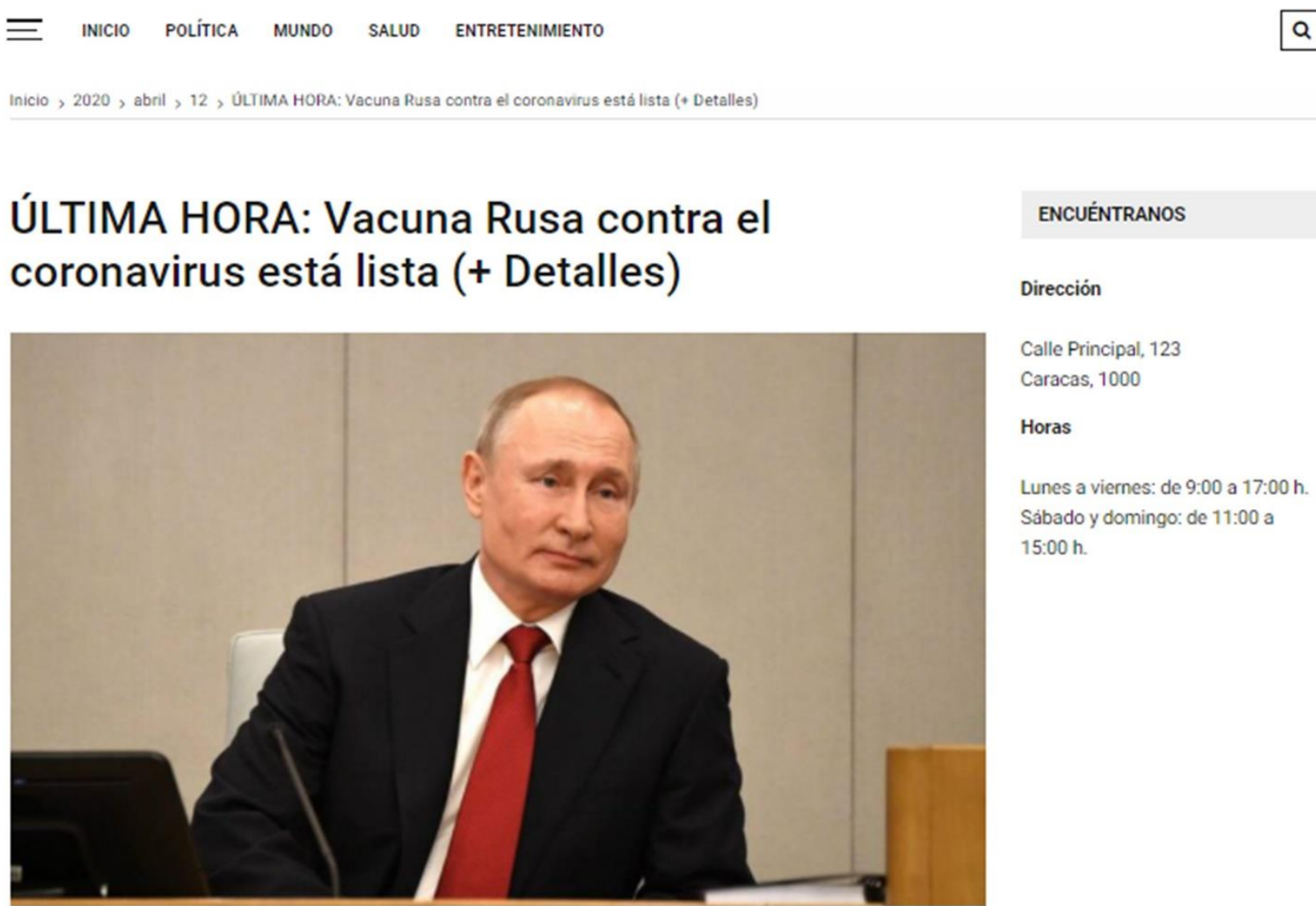

Figura 4: Bulo con intención de tráfico online (Clickbait).

Fuente: https://lanoticia24.com/.

Retomando lo mencionado por (Tandoc et al., 2018) y por (Allcott \& Gentzkow, 2017), tras la producción de noticias falsas hay motivaciones principalmente financieras e ideológicas. Las categorías Clickbait y Acciones delictivas estarían atendiendo a las motivaciones financieras, pero no es lo mismo hablar de quienes pretenden generar ganancias a través de la viralización de contenidos, que hablar de quienes buscan hacerlo por un acto ilegal. Por su parte, el Interés ideológico, relacionado con promover ideas que favorecen a ciertas personas y desacreditan a otras, con frecuencia sobrepasa su alcance. Así, en algunas ocasiones, no se refiere a individuos sino a todo un gobierno. En otros casos, se trata de generar ideas contrarias a lo que llaman 'la versión oficial' sobre temas que parecieran no tener discusión como que existe el calentamiento global o que las vacunas evitan la propagación de enfermedades. La intención antisistema es clara en ambos casos. Otros bulos tienen la intención de desestabilizar o generar pánico en la sociedad, pero no se podría decir que buscan atacar a una persona o gobierno concreto, ni al sistema político o económico hegemónico. El miedo, la desestabilización, afecta directamente a las personas del común, no al gobierno ni a un sistema.

Finalmente, la variable Carácter Transnacional se refiere a los bulos que se difundieron en diferentes países, con o sin modificaciones, como se puede apreciar en las figuras 5, 6 y 7, que señalan que el uso de tapabocas o mascarilla genera hipoxia, y que circuló en Perú, Argentina y España. 




Figura 5: Post desinformativo publicado en Facebook para la región de Puno (Perú).

Fuente: Puno Región (cuenta de Facebook). 
RLCS, Revista Latina de Comunicación Social, 78, 237-264

[Investigación] DOI: 10.4185/RLCS-2020-1476| ISSN 1138-5820| Año 2020

\section{$\leftarrow$ Thread}

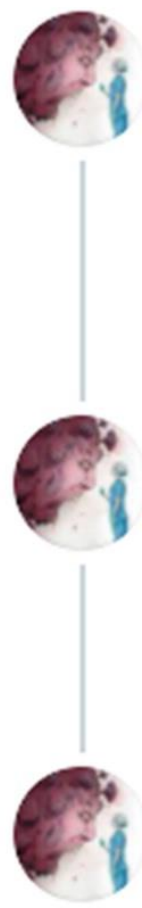

\section{Valentina @ @LaOvejaNegrah.May 1}

El uso prolongado del tapabocas produce hipoxia es decir que hay que tener en cuenta que estamos inhalando el dióxido de carbono que eliminamos al exhalar. Es por eso que podemos sentirnos cansados, con mareos o experimentar incluso visión borrosa.
23
†】 122
O 172
个

\section{Valentina @ @LaOvejaNegrah.May 1}

Los conductores de vehículos pueden presentar somnolencia y perdida de la conciencia ya que dentro de los ambientes cerrados y pequeños el intercambio de aire no se produce de la forma adecuada y necesaria.
Q 2
Ł】 22
O 34
个

\section{Valentina @ @LaOvejaNegrah.May 1}

Por eso es muy

importante recordar su uso solo en situaciones que así lo ameriten, y ventilarlos cada 10 minutos dentro de lo posible. Difundi está info
Q 1
$\uparrow \downarrow 23$
O 41
个

Figura 6: Post desinformativo tipo hilo publicado en Twitter para Buenos Aires (Argentina), según la descripción de la cuanta de la usuaria.

Fuente: @LaOvejaNegrah (cuenta de Twitter). 


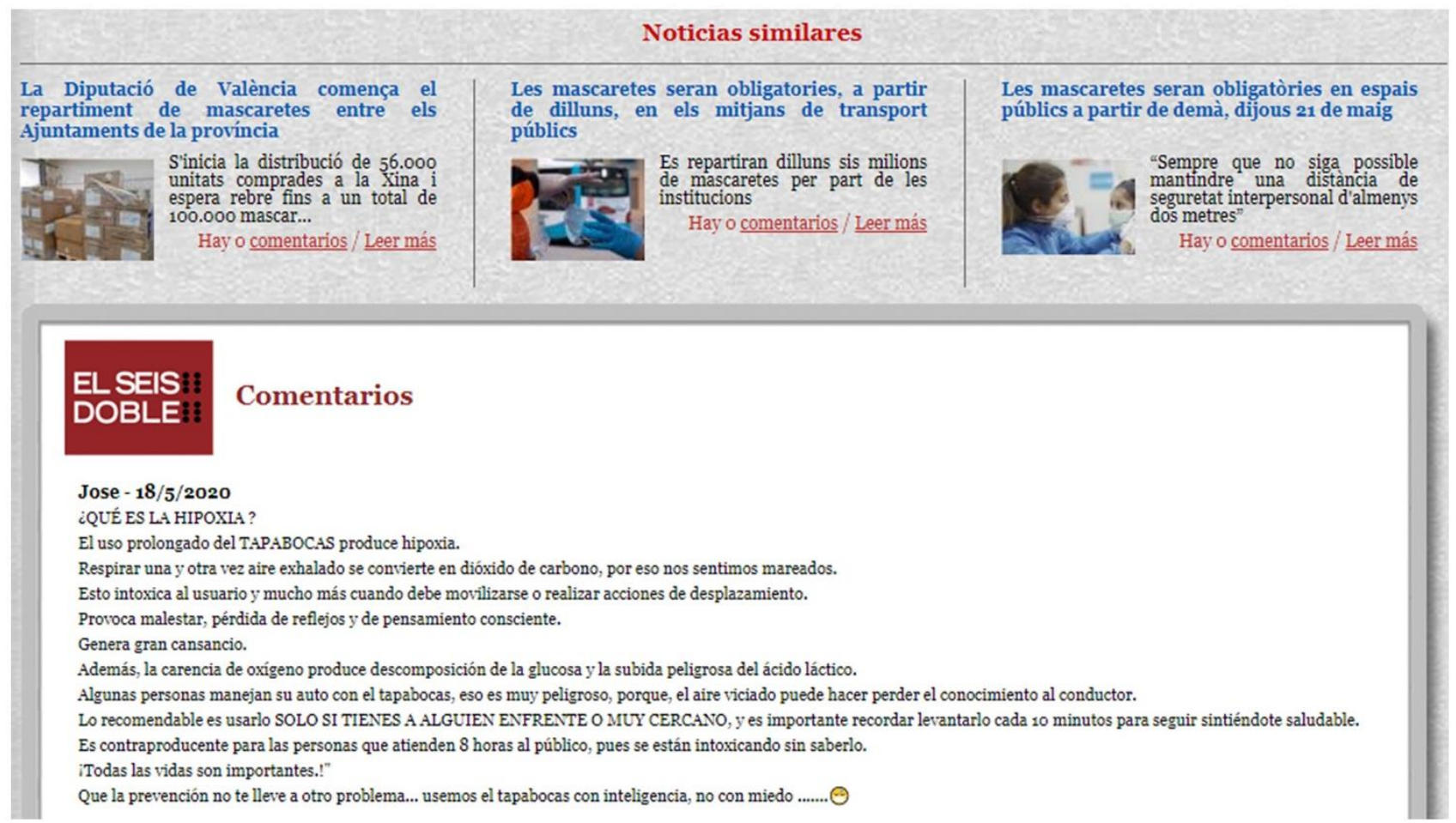

Figura 7: Comentario desinformativo publicado en una página web para la comunidad de Valencia, España.

Fuente: El Seis Doble http://www.e6d.es/noticias/el-govern-obligar-en-els-prxims-dies-a-ls-demascaretes-en-tots-els-llocs-pblics\#ad-image-0.

\subsection{Procedimiento}

Se realizó un análisis de contenido para identificar y usar los criterios de clasificación de las noticias falsas, de acuerdo con la literatura científica revisada. Con una plantilla de registro de datos, se procedió a clasificar las noticias falsas y a registrarlas según los criterios elegidos para los propósitos del presente estudio. Previo a la toma de datos, se realizó una prueba de intercodificadores con una muestra aleatoria de 10 registros. Se hallaron coincidencias superiores a 0,76 y hasta del 100\%, según el estadígrafo Kappa, en las diferentes variables del instrumento. Los análisis comparativos se realizaron con el paquete estadístico SPSS, versión 24.

\section{Resultados}

El análisis de los datos permite dar un panorama de las principales características de los bulos que circularon en cada uno de los países de la muestra. En primer lugar, se pudo evidenciar que Facebook fue la red más empleada para divulgar noticias falsas, ya que se usó en el 32,9\% de los 371 casos analizados. El segundo puesto fue para los bulos que se difundieron en dos o más redes, los cuales correspondieron al 31,9\%. Les siguieron WhatsApp, con $21 \%$; Twitter con $5,7 \%$, Correos o SMS con el 5,4\% y YouTube con el 3,0\%. Al analizar el peso de los canales de distribución dentro de cada país, se encontró que en Colombia (33,8\%), Argentina (53,1\%), Ecuador (60\%) y Bolivia (51,9\%), predominó el uso de Facebook, mientras en España (40,3\%) y Perú $(42,9 \%)$ circularon por dos más redes a la vez (Coef. De Contingencia $=0,45 ; p<0,05)$. 
RLCS, Revista Latina de Comunicación Social, 78, 237-264

[Investigación] DOI: 10.4185/RLCS-2020-1476| ISSN 1138-5820| Año 2020

El formato más frecuente que se empleó para hacer circular el contenido falso fue el texto (40,2\%), ya que es de fácil acceso y se puede manipular al antojo de quien lo realiza. También se detectó un porcentaje significativo para los bulos que emplearon imagen-texto, el 26,1\%. (Ver Gráfico 1).

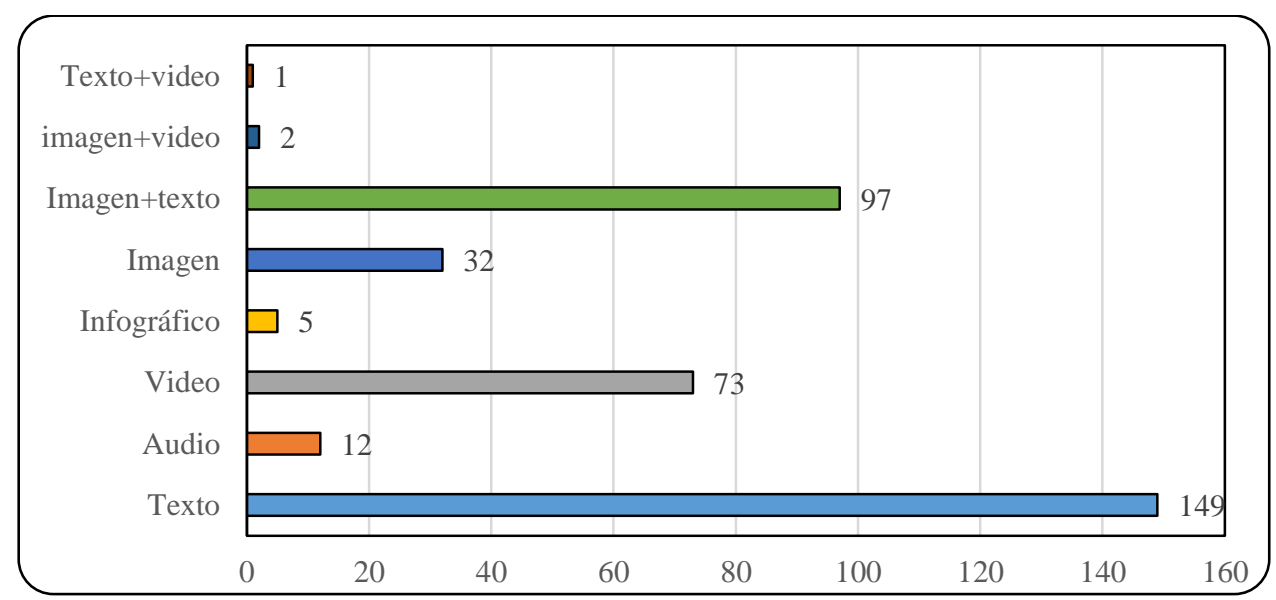

Gráfico 1. Formatos en los que circularon los bulos sobre el Covid-19.

Fuente: Elaboración con base en la muestra de bulos analizados.

Cuando se observa país por país, se encuentran algunas diferencias en los formatos de distribución de bulos. En Colombia predominó el uso de texto (37,2\%), seguido de Imagen-texto (35,9\%); en España, texto (47,6\%), seguido de video (20,2\%); en Argentina, texto $(53,1 \%)$ y en segundo lugar Imagen (22,4\%); en Ecuador, Imagen-texto (41,5\%) y después texto (32,3\%); en Bolivia, texto $(29,6 \%)$, seguido en igualdad de porcentaje por video e imagen-texto (25,9\% cada uno), y en Perú, imagen-texto $(50 \%)$, seguido de video $(25 \%)$ (Coef. De Contingencia $=0.44 ; p<0.05)$.

En relación con la procedencia o ámbito de los bulos predominan los nacionales con 48,2\% y una frecuencia de 175. Los de ámbito internacional tienen un 44,2\% y los locales sólo obtienen un 7,5\%. Sin embargo, el análisis individual de cada país muestra que en España, Bolivia y Perú circularon con mayor frecuencia las noticias falsas de ámbito internacional (45,2\%; 59,3\% y 64,3\% respectivamente), mientras en Ecuador, Colombia y Argentina, predominaron las de ámbito nacional $(64,6 \% ; 52,6 \%$ y 44,9\% respectivamente) (Coef. De Contingencia $=0.27 ; p<0.05)$.

El tipo de bulo que más se registró fue el Contenido engañoso, con el $79 \%$, seguido del Contenido impostor, es decir, aquel en que se suplantan fuentes genuinas, $14,6 \%$, y la sátira o parodia, con el $6,5 \%$. Las asociaciones entre el tipo de bulo y el país no fueron estadísticamente significativas.

La técnica de engaño más utilizada fue el contexto falso, que hace alusión al contenido genuino que se difunde con información de contexto distorsionada, y que se registró en el 51,8\% de los casos. En segundo lugar, se registró el contenido fabricado, es decir, contenido nuevo diseñado para engañar y perjudicar, que apareció en el 32,1\%. Las demás categorías se presentaron en pocas ocasiones (Ver Gráfico 2). 
RLCS, Revista Latina de Comunicación Social, 78, 237-264

[Investigación] DOI: 10.4185/RLCS-2020-1476| ISSN 1138-5820| Año 2020

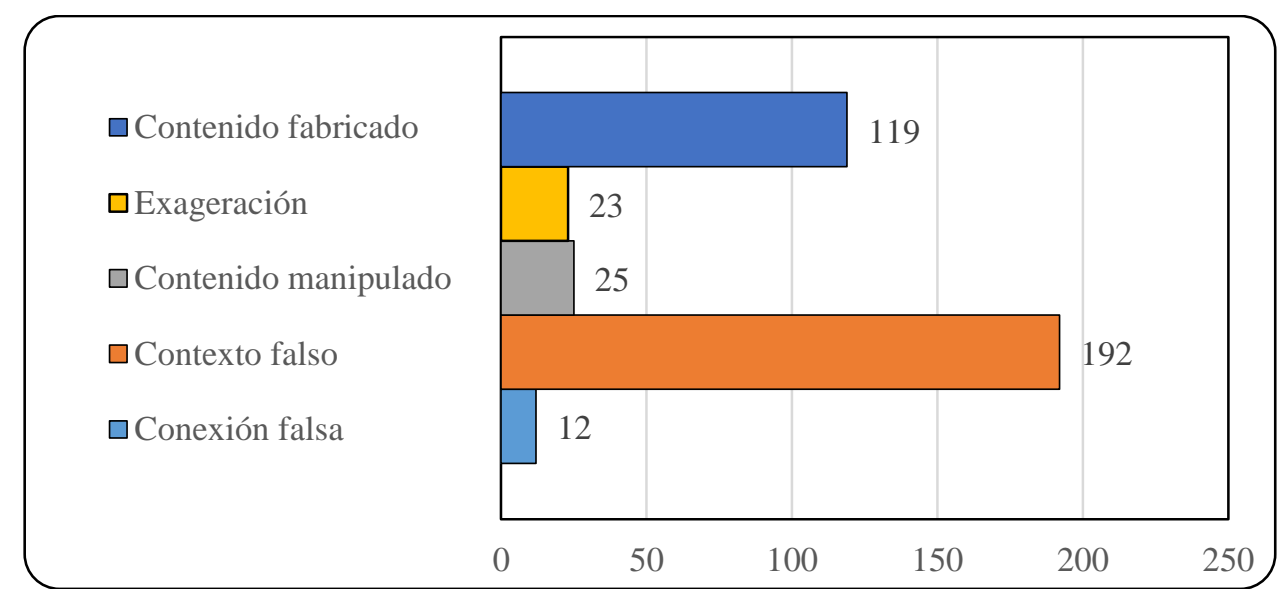

Gráfico 2. Técnicas de engaño más utilizadas en los bulos sobre el Covid-19. Fuente: Elaboración con base en la muestra de bulos analizados.

Por países, se observa que Colombia, España, Ecuador y Perú mantienen la misma tendencia. Sin embargo, en el caso de Argentina, la técnica más utilizada es el contenido fabricado $(57,1 \%)$, seguido del contexto falso $(28,6 \%)$ y en el caso de Bolivia el primero es el contexto falso $(33,3 \%)$ y le sigue el contenido manipulado, es decir, modificado intencionalmente con herramientas tecnológicas $(29,6 \%)$ (Coef. De Contingencia $=0,39 ; p<0,05)$.

En cuanto a la variable intencionalidad, es decir, el propósito que tienen las personas al momento de hacer circular el bulo, predominó la categoría de Interés ideológico, definida como el deseo de desacreditar o acreditar gobiernos o introducir debates antisistema, que se registró en el 40,4\% de los casos. Le siguieron el Clickbait, o interés por obtener mayor cantidad de reproducciones en las redes, con el 32,3\%; Desestabilizar o generar pánico, con el 20,8\% y las Acciones delictivas, cuyo interés es la obtención de datos personales para estafar o robar a la gente, con un 6,5\%. Si se mira por países, la intencionalidad mayoritariamente ideológica, se mantiene en España, Argentina y Ecuador, donde ocupan altos porcentajes con respecto a sus propios bulos $(54,8 \%, 49,2 \%$ y 46,2\%, respectivamente). En Colombia, Bolivia y Perú predomina el Clickbait (43,6\%, 51,9\% y 60,7\%, respectivamente). (Coef. De Contingencia $=0.38 ; p<0.05$ ).

La fuente con mayor frecuencia es la anónima $(80,6 \%)$, porque no tiene un sujeto que se haga responsable de lo publicado, tampoco tiene respaldo científico, académico, político o estatal. Las fuentes reales, es decir, aquellas personas o entidades conocidas que se identifican claramente a pesar de que la información sea falsa, ocuparon el 11,9\%; las fuentes suplantadas, donde se toma el nombre de personas o instituciones para atribuirles acciones o declaraciones que no han realizado, correspondieron al $4 \%$ y las ficticias o inventadas al 3,5\%. La tendencia se mantiene igual en cada uno de los países al observar los datos de manera individual (Coef. De Contingencia $=0.35 ; p<0.05$ ).

Apenas un 6,7\% del total de noticias falsas analizadas fue reproducido en medios de comunicación, lo que sugiere la existencia de un filtro adecuado de confirmación antes de publicar este tipo de informaciones que circulan por redes sociales. Sólo en Argentina y Colombia, cerca del 14\% de los bulos fueron publicados en medios mientras en Bolivia y Perú no se presentó ningún caso (Coef. De Contingencia $=0.21 ; p<0.05)$.

El tema que circuló mayoritariamente en el conjunto de países analizado fue el relacionado con los Falsos anuncios o acciones de un Gobierno, de organizaciones o personajes públicos, el cual 
RLCS, Revista Latina de Comunicación Social, 78, 237-264

[Investigación] DOI: 10.4185/RLCS-2020-1476| ISSN 1138-5820| Año 2020

correspondió al 31,5\%. Le siguieron las categorías de Supuestas curas y consejos de salud, con el 26,1\%; y la Situación de un país, con el 16,2 \% (Ver Gráfico 3).

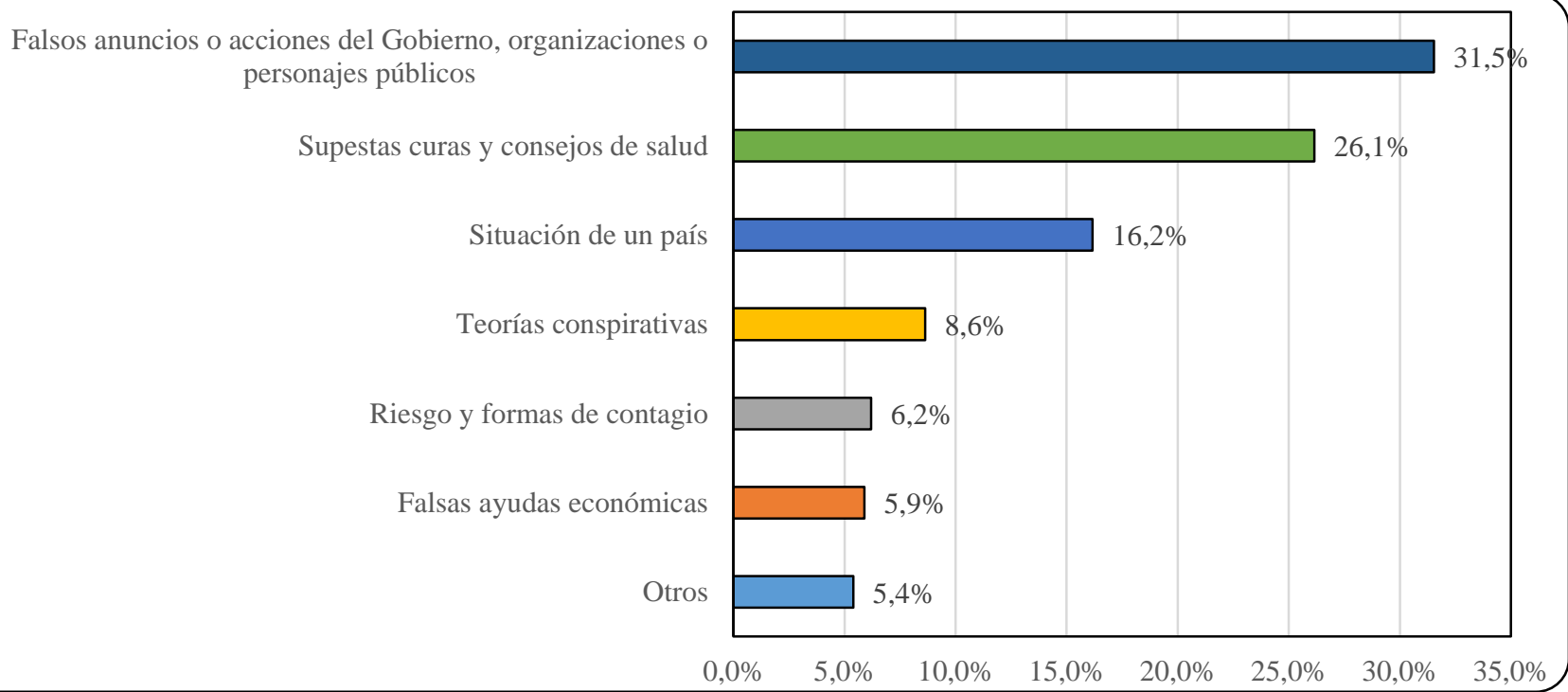

Gráfico 3. Temas más comunes de noticias falsas sobre el Covid-19.

Fuente: Elaboración con base en la muestra de bulos analizados.

Se halló una alta asociación (Coef. De Contingencia $=0.83 ; p<0.05$ ) entre los países y los temas de los bulos que más circularon. Los falsos anuncios de entidades y/o personajes públicos fue el tema de bulo más recurrente en España, Argentina y Ecuador, seguido por las supuestas curas, que fue el tema más repetido en Colombia, Bolivia y Perú (Ver Tabla 1).

En las noticias falsas difundidas aparecen los presidentes de los diversos países y otros personajes públicos como políticos, rey o reina, anunciando supuestamente fechas para iniciar o terminar el proceso de confinamiento, el tiempo de prolongación de la cuarentena, o aparentes castigos para quienes incumplan las reglas de aislamiento social. Fue común encontrar a personajes de la política vinculados aparentemente con asociaciones (inter)nacionales de atención humanitaria que fueron señalados, por ejemplo, por incumplimiento de las normas del confinamiento. También aparecieron múltiples anuncios de supuestos nombramientos de personajes en altos puestos gubernamentales, lo que indica una manipulación de la información con intención de desprestigiar a los personajes y, tácitamente, a su gestión.

Tabla 1. Temas de las noticias falsas que circularon en seis países iberoamericanos

Tema

Falsos anuncios

o acciones del

Gobierno,

Organizaciones o

Personajes

públicos

Riesgo y formas

de contagio

Supuestas curas

$\begin{array}{llllllll}y & \text { consejos de } & 34 & 9.2 \% & 15 & 4.0 \% & 8 & 2.2 \%\end{array}$

salud

$9 \quad 2.4 \% \quad 58 \quad 15.6 \%$

$6 \quad 1.6 \% \quad 6 \quad 1.6 \%$

$5 \quad 1.3 \%$

\begin{tabular}{crrrr} 
Colombia & \multicolumn{2}{c}{ España } & \multicolumn{2}{c}{ Argentina } \\
F & $\%$ & F & $\%$ & F
\end{tabular}

$20.5 \%$

$1 \quad 0.3 \%$

$30.8 \%$

$12 \quad 3.2 \%$

$12 \quad 3.2 \%$

$16 \quad 4.3 \%$ 
RLCS, Revista Latina de Comunicación Social, 78, 237-264

[Investigación] DOI: 10.4185/RLCS-2020-1476| ISSN 1138-5820| Año 2020

\begin{tabular}{|c|c|c|c|c|c|c|c|c|c|c|c|c|}
\hline \multirow{2}{*}{ Tema } & \multicolumn{2}{|c|}{ Colombia } & \multicolumn{2}{|c|}{ España } & \multicolumn{2}{|c|}{ Argentina } & \multicolumn{2}{|c|}{ Ecuador } & \multicolumn{2}{|c|}{ Bolivia } & \multicolumn{2}{|c|}{ Perú } \\
\hline & $\mathrm{F}$ & $\%$ & $\mathrm{~F}$ & $\%$ & $\mathrm{~F}$ & $\%$ & F & $\%$ & $\mathrm{~F}$ & $\%$ & $\mathrm{~F}$ & $\%$ \\
\hline $\begin{array}{l}\text { Falsas ayudas } \\
\text { económicas }\end{array}$ & 2 & $0.5 \%$ & 10 & $2.7 \%$ & 2 & $0.5 \%$ & 7 & $1.9 \%$ & 1 & $0.3 \%$ & 0 & $0.0 \%$ \\
\hline $\begin{array}{l}\text { Teorías } \\
\text { conspirativas }\end{array}$ & 8 & $2.2 \%$ & 10 & $2.7 \%$ & 6 & $1.6 \%$ & 7 & $1.9 \%$ & 0 & $0.0 \%$ & 1 & $0.3 \%$ \\
\hline $\begin{array}{l}\text { Situación de un } \\
\text { país }\end{array}$ & 17 & $4.6 \%$ & 17 & $4.6 \%$ & 4 & $1.1 \%$ & 12 & $3.2 \%$ & 4 & $1.1 \%$ & 6 & $1.6 \%$ \\
\hline Otros & 2 & $0.5 \%$ & 8 & $2.2 \%$ & 4 & $1.1 \%$ & 2 & $0.5 \%$ & 2 & $0.5 \%$ & 2 & $0.5 \%$ \\
\hline Total & 78 & $21.0 \%$ & 124 & $33.4 \%$ & 49 & $13.2 \%$ & 65 & $17.5 \%$ & 27 & $7.3 \%$ & 28 & 371 \\
\hline
\end{tabular}

Fuente: Elaboración con base en la muestra de bulos analizados.

\section{1. ¿Cómo se construyen los bulos y con qué intención?}

Entender cómo se construyen las noticias falsas y la intención que pueden tener quienes las producen, es el primer paso para poder combatirlas. La relación entre el tema y la intencionalidad (Coef. De Contingencia $=0.73 ; p<0.05$ ) da cuenta de que tras los Falsos anuncios o acciones del Gobierno, organizaciones o personajes públicos hay un interés ideológico de desacreditar o acreditar gobiernos o de introducir debates antisistema o de respaldo al sistema. Le sigue el tema de Supuestas curas y consejos de salud relacionado con la intención de generar tráfico o un número grande de interacciones (Ver Gráfico 4).

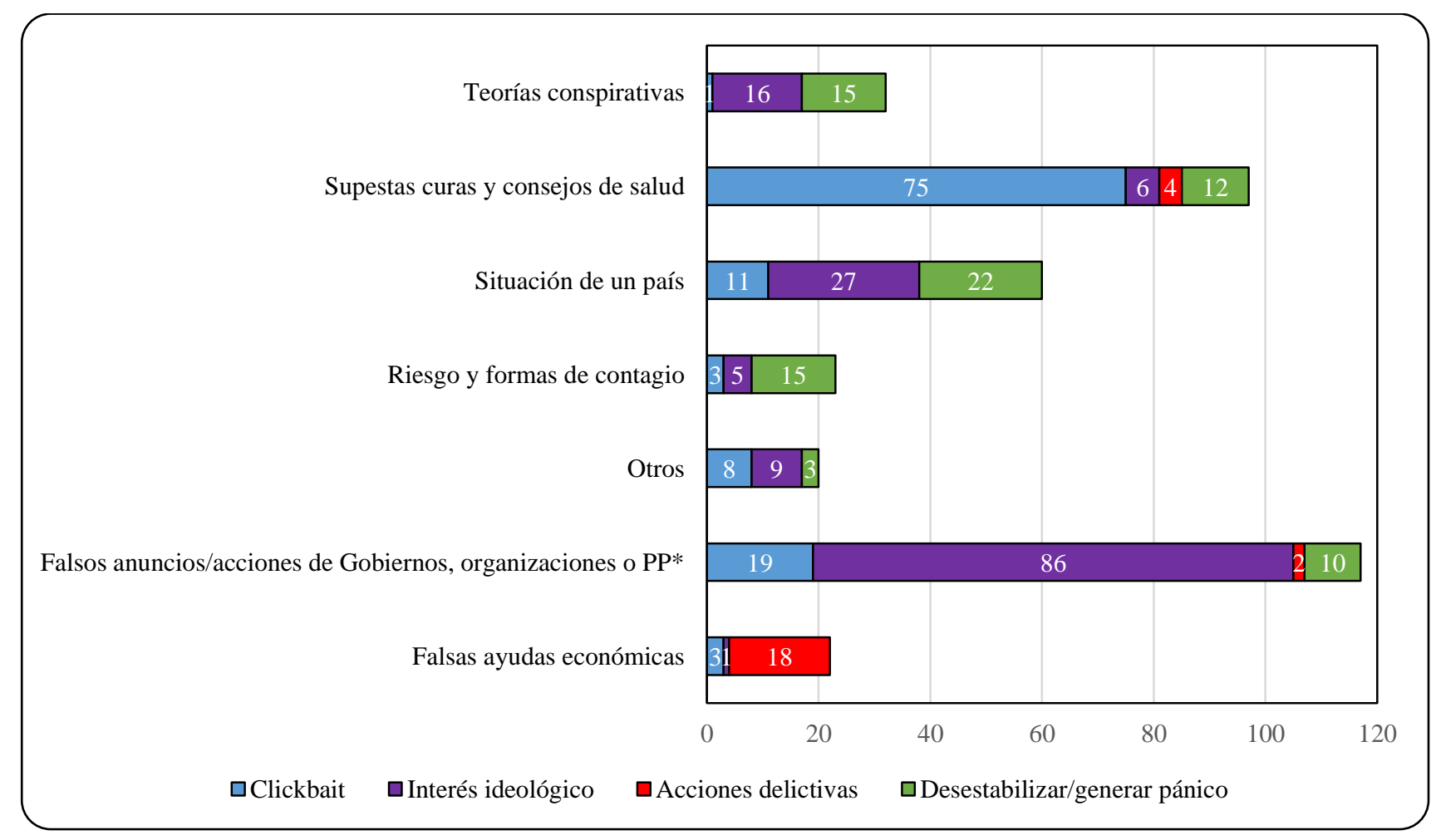

Gráfico 4. Frecuencia de intencionalidades del bulo y los temas vinculados.

* PP= Personajes Públicos

Fuente: Elaboración con base en la muestra de bulos analizados.

Igualmente, hay una asociación significativa, aunque moderada, entre la técnica de engaño y la intencionalidad (Coef. De Contingencia $=0.40 ; p<0.05$ ). Se evidencia que el contexto falso es la técnica más utilizada en relación con casi todas las intencionalidades, probablemente porque es más 
fácil basarse en informaciones reales, pero modificando aspectos como el lugar en el que ocurre, los protagonistas o la manera en que han acontecido los hechos. La segunda técnica más utilizada es fabricar contenidos, aunque se asocia principalmente con el Clickbait (Ver Tabla 2).

Tabla 2. Temas de las noticias falsas que circularon en seis países iberoamericanos

\begin{tabular}{lcccccccc}
\multicolumn{1}{c}{ Técnica de engaño } & Clickbait & Interés ideológico & Acciones delictivas & $\begin{array}{c}\text { Desestabilizar } \\
\text { o generar } \\
\text { pánico }\end{array}$ \\
& F & $\%$ & $\mathrm{~F}$ & $\%$ & $\mathrm{~F}$ & $\%$ & $\mathrm{~F}$ & $\%$ \\
Conexión falsa & 7 & $1.9 \%$ & 3 & $0.8 \%$ & 0 & $0.0 \%$ & 2 & $0.5 \%$ \\
Contexto falso & 49 & $13.2 \%$ & 99 & $26.7 \%$ & 3 & $0.8 \%$ & 41 & $11.1 \%$ \\
Contenido manipulado & 3 & $0.8 \%$ & 18 & $4.9 \%$ & 0 & $0.0 \%$ & 4 & $1.1 \%$ \\
Exageración & 15 & $4.0 \%$ & 3 & $0.8 \%$ & 2 & $0.5 \%$ & 3 & $0.8 \%$ \\
Contenido fabricado & 46 & $12.4 \%$ & 27 & $7.3 \%$ & 19 & $5.1 \%$ & 27 & $7.3 \%$
\end{tabular}

Fuente: Elaboración con base en la muestra de bulos analizados.

La asociación entre las técnicas de engaño y los tipos de noticias falsas es apenas notable pero significativa (Coef. De Contingencia $=0.33 ; p<0.05$ ), asumiendo el tipo de bulo como variable dependiente. Las asociaciones más representativas se dieron entre el contexto falso como técnica de engaño y el contenido engañoso como tipo de bulo, lo que quiere decir que aun cuando la base de la información pudiese ser cierta, se modificaba el contexto o detalles que terminaban por hacerla falsa. La segunda técnica más utilizada fue el contenido fabricado, es decir, completamente inventado con el objetivo de desinformar, relacionado con el contenido engañoso (Ver tabla 3).

Tabla 3. Técnicas de engaño según los tipos de noticias falsas detectadas.

\begin{tabular}{lccccccc}
\multicolumn{1}{c}{ Tipo de bulo } & \multicolumn{1}{c}{ Sátira o parodia } & \multicolumn{3}{c}{ Contenido engañoso } & \multicolumn{2}{c}{ Contenido impostor } & Total \\
& $\mathrm{F}$ & $\%$ & $\mathrm{~F}$ & $\%$ & $\mathrm{~F}$ & $\%$ & $\mathrm{~N}$ \\
Conexión falsa & 1 & $8.3 \%$ & 11 & $91.7 \%$ & 0 & $0.0 \%$ & 12 \\
Contexto falso & 11 & $5.7 \%$ & 169 & $88.0 \%$ & 12 & $6.3 \%$ & 192 \\
Contenido manipulado & 1 & $4.0 \%$ & 15 & $60.0 \%$ & 9 & $36.0 \%$ & 25 \\
Exageración & 2 & $8.7 \%$ & 21 & $91.3 \%$ & 0 & $0.0 \%$ & 23 \\
Contenido fabricado & 9 & $7.6 \%$ & 77 & $64.7 \%$ & 33 & $27.7 \%$ & 119
\end{tabular}

Fuente: Elaboración con base en la muestra de bulos analizados.

\subsection{Desinformación que traspasan fronteras}

La desinformación de carácter transnacional merece especial atención porque puede ayudar a establecer las características de los bulos que circulan con mayor alcance, ya que se repiten en distintos países. Al observar en detalle los bulos durante el periodo estudiado, se encontraron coincidencias en 27 desinformaciones que circulaban en varios países, representadas en 100 noticias (26,9\% de la muestra). En algunas de ellas se repetían temas, con similar tratamiento, aun cuando variaban los formatos de presentación. Es el caso de las supuestas curas con vaporizaciones de eucalipto o con dióxido de cloro, que en algunas ocasiones circularon en texto y otras en video, y en esencia trataban de convencer a las personas de seguir un determinado tratamiento (Ver Tabla 4). 
RLCS, Revista Latina de Comunicación Social, 78, 237-264

[Investigación] DOI: 10.4185/RLCS-2020-1476| ISSN 1138-5820| Año 2020

Tabla 4. Frecuencias con la que los bulos circularon en diferentes países de Iberoamérica.

Desinformación

El dióxido de cloro cura el coronavirus.

Consumir alimentos alcalinos ayuda a combatir el coronavirus.

El COVID-19 es un exosoma y es causado por el 5G. Hay un plan para esparcirlo por el mundo.

El uso prolongado de mascarilla produce hipoxia.

El jengibre, el limón, la cebolla y el ajo juntos neutralizan el Covid-19.

Tasuku Honjo, premio Nobel de Medicina 2018, dijo que "el coronavirus fue fabricado por el hombre".

Hacer vaporizaciones con eucalipto cura el coronavirus

Foto del supuesto médico que murió por coronavirus o que buscaba la cura a la enfermedad.

Beber agua de mar evita contagio de coronavirus.

En Italia descubrieron que la COVID-19 causa trombosis en vez de neumonía haciendo autopsias.

La Fundación Gates se describe como un centro para la reducción de la población.

El COVID-19 fue hecho en un laboratorio chino.

Se está entregando una tarjeta alimentaria.

Video de bolsas negras con cadáveres.

Hacer gárgaras con bicarbonato de sodio y agua caliente mata al coronavirus.

El calor del secador de pelo elimina el Covid-19.

El café cura el Covid-19.

En Italia lanzaron billetes a la calle para demostrar que la salud no se compra con dinero.

Gobierno Nacional dispuso de estas fechas para activar sectores productivos.

Rusia tiene una vacuna lista para el Covid-19.

Washington Post confirmó que paciente cero de COVID-19 trabajaba en laboratorio de Wuhan.

El coronavirus se combate sólo con tratamientos contra la trombosis.

Video donde aparecen cadáveres hacinados en el suelo en bolsas negras.

La COVID-19 es una bacteria que se cura con aspirina.

Han muerto 232 niños por COVID-19 en Italia.

El tipo de sangre influye en la vulnerabilidad frente al COVID-19.

Una foto de un periódico de 2003 que habla del coronavirus actual.

\begin{tabular}{|c|c|}
\hline $\begin{array}{l}\text { Número de } \\
\text { noticias en las } \\
\text { que se repite }\end{array}$ & $\begin{array}{l}\text { Número de } \\
\text { países en los } \\
\text { que circuló }\end{array}$ \\
\hline 9 & 5 \\
\hline 6 & 5 \\
\hline 14 & 5 \\
\hline 7 & 5 \\
\hline 5 & 4 \\
\hline 4 & 4 \\
\hline 6 & 3 \\
\hline 5 & 3 \\
\hline 3 & 3 \\
\hline 3 & 3 \\
\hline 4 & 3 \\
\hline 2 & 2 \\
\hline 3 & 2 \\
\hline 2 & 2 \\
\hline 2 & 2 \\
\hline 2 & 2 \\
\hline 2 & 2 \\
\hline 2 & 2 \\
\hline 3 & 2 \\
\hline 2 & 2 \\
\hline 2 & 2 \\
\hline 2 & 2 \\
\hline 2 & 2 \\
\hline 4 & 2 \\
\hline 2 & 2 \\
\hline 2 & 2 \\
\hline 2 & 2 \\
\hline
\end{tabular}

Fuente: Elaboración con base en la submuestra de bulos transnacionales.

Hubo ocasiones en las que una misma noticia abordaba distintas desinformaciones sobre un tema, como los supuestos efectos de la tecnología 5G, que en algunos países circuló como causa del coronavirus y en otros se asoció a un plan conspirativo para esparcir el Covid-19 a través de las antenas. En otras noticias falsas de carácter transnacional se repetía la imagen, pero el texto se adaptaba al contexto de cada país en el que circularon. Por ejemplo, se utilizó una foto del actor porno español Ángel Muñoz, vestido de médico, para informar sobre la supuesta muerte de un joven doctor mientras atendía pacientes infectados. En cada país cambiaba el nombre que se daba al supuesto galeno o el de la institución para la cual trabajaba. La misma imagen fue difundida anunciando que se trataba de un médico que aparentemente trabajaba en la búsqueda de una vacuna contra el virus. Por esta razón, en algunos casos un mismo bulo se clasificó en distintas categorías de temas, según el país y el contenido falso que se difundía.

Los temas predominantes en las desinformaciones de carácter transnacional fueron las falsas curas y consejos de salud (54\%); seguidas por las teorías conspirativas (12\%), y los falsos anuncios o acciones del Gobierno, organizaciones o personajes públicos, con un 11\% (Ver Gráfico 5). 
RLCS, Revista Latina de Comunicación Social, 78, 237-264

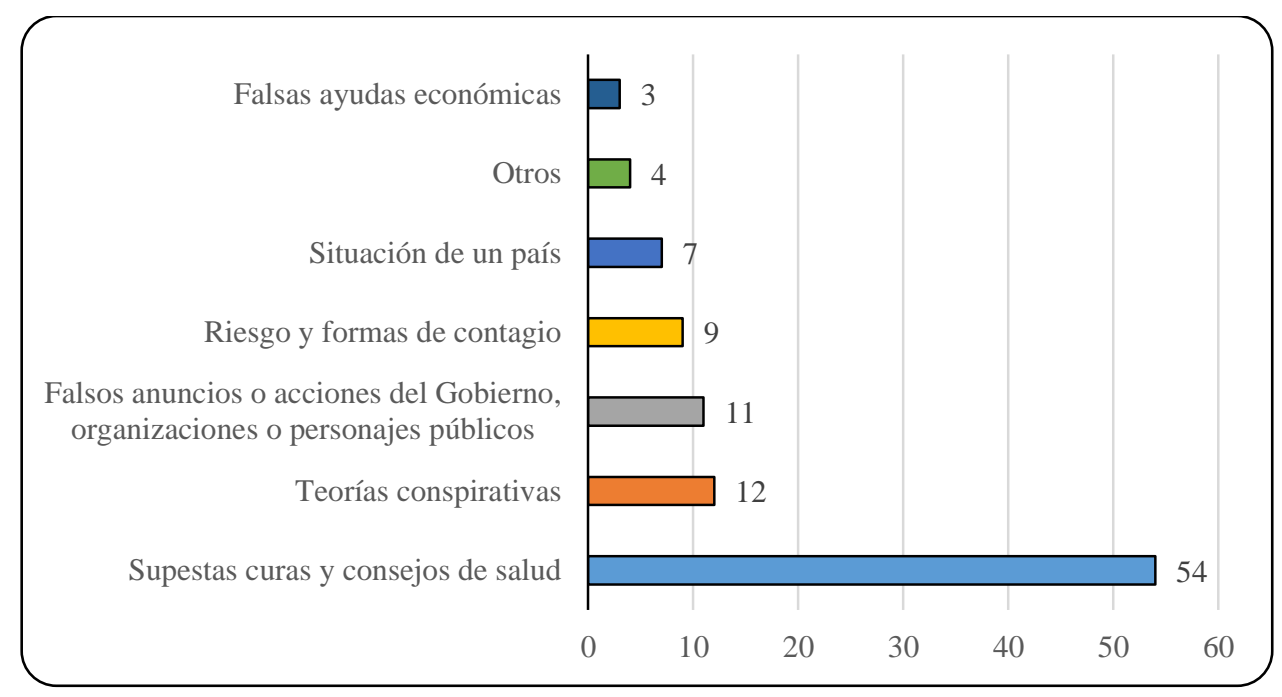

Gráfico 5. Temas transnacionales de bulo.

Fuente: Elaboración con base en la submuestra de bulos transnacionales.

Los temas más proclives a viralizarse transnacionalmente fueron aquellos que dan al lector esperanzas para protegerse del contagio, creados con técnicas que resultan verosímiles, aun cuando estén basadas en contenido fabricado (34\%) o en la exageración de las propiedades medicinales de ciertos elementos que han servido tradicionalmente a las comunidades para aplacar los síntomas de la gripe $(10 \%)$. La asociación resultó ser moderada, pero estadísticamente significativa, entre estas variables (Coef. De contingencia $=0,54 ; p=0,02$ ).

La intencionalidad principal de los bulos transnacionales es el Clickbait (54\%), seguida del interés por generar pánico o desestabilizar (22\%), el interés ideológico (19\%) y las acciones delictivas (5\%). La asociación entre estas variables en relativamente alta (Coef. de contingencia $=0,72 ; p=0,000)$. En el caso de las falsas curas y consejos de salud, la principal intención fue la de obtener una difusión viral del mensaje (41\%), que podrían ocultar razones comerciales, como en el caso del dióxido de cloro, que era promocionado como una cura milagrosa para diversas enfermedades.

Otra característica de los bulos que traspasaron fronteras fue que suelen ser mayoritariamente supuestas noticias de origen internacional 69\%, lo que facilita su circulación sin modificación. Las desinformaciones de ámbito nacional (29\%) y local (2\%), suelen requerir cambios para pasar de un país a otro, como en el caso de los anuncios de fechas para reactivar la economía, donde había contenido creado para cada país.

Estas desinformaciones de ámbito internacional tuvieron como intención predominante la de generar reproducciones (Clickbaits, 37\%), seguidas por desestabilizar o generar pánico (16\%) y de interés ideológico (15\%) (Coef. de Contingencia $=0,38 ; p=0,008)$.

Finalmente, se halló relación estadísticamente significativa, con una asociación moderada (Coef. de Contingencia $=0,53 ; p=0,027$ ) entre el formato y la técnica de engaño utilizada en los bulos de carácter transnacional. El contenido fabricado circuló principalmente como texto (26\%), seguido de video (17\%) e imagen acompañada de texto (12\%). Entre tanto, los bulos en los que la información de base era real, pero se falseaba en contexto se difundieron como imagen con texto (13\%) y como texto (10\%) (Ver Gráfico 6). 
RLCS, Revista Latina de Comunicación Social, 78, 237-264

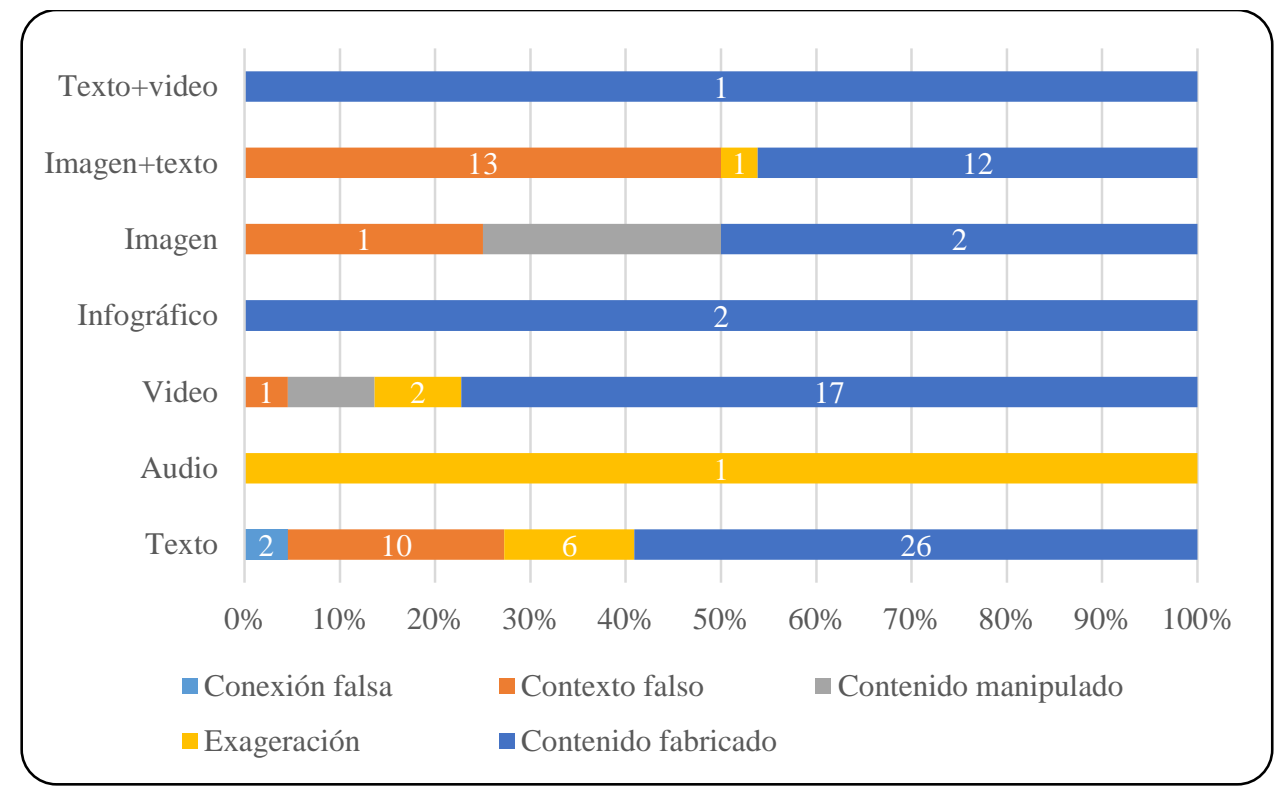

Gráfico 6. Formato y técnicas de engaño usadas en bulos transnacionales. Fuente: Elaboración con base en la submuestra de bulos transnacionales.

\section{Discusión y Conclusiones}

El presente estudio, referido a las noticias falsas sobre Covid-19 que circularon en 6 países iberoamericanos, muestra un análisis comparativo en torno a los temas recurrentes, la relación entre el tipo de noticias falsas y la técnica de engaño que emplean los desinformadores y la identificación de sus posibles intencionalidades. La comparación de las noticias falsas que traspasaron fronteras estableció posibles elementos que favorecen su carácter transnacional, lo cual constituye una diferencia de aquellas investigaciones que se centran en las noticias de un solo país (Brennen et al., 2020; Salaverría et al., 2020), pues evidencia las características de aquellos bulos susceptibles de circular internacionalmente por su carácter general e indiferenciado y que tienen en común desinformación que apela principalmente a la emoción, más que a individuos concretos. Algunos de estos bulos tenían carácter satírico, como los que usaban fotos de actores porno vestidos de médicos, pero solo quienes conocían los personajes podrían catalogar la información como noticia falsa.

Este estudio muestra que las redes sociales, al ser seleccionadas para que circulen las noticias falsas, están afectando de manera importante a la producción de información, pues tal como afirma (Alonso González, 2019), en la medida en que las noticias creadas por cualquier persona conviven con las noticias generadas por periodistas y multiplican el efecto de superabundancia informativa que, unido al anonimato que facilitan las plataformas digitales, se convierte en un caldo de cultivo idóneo para la proliferación de noticias falsas, así como de la difícil identificación de los hechos verdaderos para la audiencia.

La diferencia de los términos información errónea (Misinformation) y desinformación que propone Wardle (2017) es discutible ya que también hay diferencia entre malinterpretar información (cierta o falsa) y compartirla. En ambos casos, reiterar la recomendación de promover un pensamiento crítico sobre contenidos 'novedosos' o inusuales, tiene especial relevancia en tiempos de pandemia e incertidumbre ya que es el usuario de la información el responsable de que la (des)información se propague o no. 
Según los hallazgos de la presente investigación, Facebook sigue siendo, en el contexto de los seis países analizados, la plataforma por la cual circulan con mayor frecuencia los bulos, seguido de las noticias falsas que circularon por dos o más plataformas a la vez, como Twitter, WhatsApp y YouTube. Esta es una diferencia de lo reportado por (Salaverría et al., 2020) quienes destacan el poder de WhatsApp como la plataforma por donde "los bulos se diseminan en mayor cantidad y con mayor alcance" (pág,11). Esto, aunque puede ser cierto para el caso de España, tiene un matiz importante, porque según lo hallado, tanto para Perú como para España el primer lugar en distribución de bulos es compartido por varias redes sociales a la vez.

Facebook ha intentado combatir la diseminación de noticias falsas, pero la falta de alfabetización en noticias (news literacy) por parte del público dificulta la toma de decisiones para elegir y desechar noticias y fuentes dudosas, de aquellas en las que se podría confiar. Los proyectos Facebook Journalism Project y New Integrity Initiative (Aspray \& Cortada, 2019; Cortés \& Isaza, 2017), monitorean el efecto de las noticias falsas en el público e informan a dicha red social virtual para procurar una mejor alfabetización en las audiencias, al tiempo que sugiere mejores filtros cibernéticos contra los bulos. Este tipo de iniciativas se deberían fomentar, al igual que la consulta de portales o iniciativas de periodismo de verificación (fact-checking journalism), las cuales cumplen con el propósito de alfabetizar a la audiencia al proporcionar un servicio que clarifica y clasifica la información en verdadera, falsa o dudosa, de manera que las personas puedan tomar determinaciones sobre la información que consumen (Elizabeth, 2014). Si bien esta práctica informativa no impediría la difusión de noticias falsas, como lo plantean (Nielsen \& Graves, 2017), resulta ser una herramienta alternativa al consumo indiscriminado de información On/Offline.

Por otra parte, la caracterización de las noticias falsas muestra cómo algunos tipos de formato, técnicas de desinformación, temas y ámbito al que se refieren las noticias falsas, se usan con mayor frecuencia, lo cual hace pensar que aumentan las posibilidades de difusión de los bulos. Así, el formato más frecuentemente empleado fue el texto, dada la facilidad para manipularlo y distribuirlo por redes sociales, aplicaciones de mensajería o correos electrónicos; seguido del uso de imágenes y textos en el mensaje falso, que apela a la sensibilidad del lector, al pathos descrito por Aristóteles (Johnson \& Stavru, 2019), es decir, a la empatía de la audiencia.

La mayoría de las desinformaciones fueron elaboradas con la técnica de contexto falso, es decir que, sobre una información usualmente verídica, se hacen modificaciones o reconfiguraciones para conseguir un efecto diferente al hecho que la produce, como ya se ha encontrado previamente en otras investigaciones (Brennen et al., 2020). Otra buena parte de los contenidos son completamente fabricados y esto supone que sus creadores utilicen técnicas de engagement, pensadas para generar conexión emocional con los receptores del mensaje, de ahí que las noticias falsas transnacionales estuvieron centradas en las posibles curas o tratamientos para combatir el Covid-19, seguidas por las teorías conspirativas y las menciones a la situación de un país distinto al propio, siempre alarmantes por la referencia a contagios o muertes. Se aprovecha entonces la vulnerabilidad de las personas y el miedo e incertidumbre para construir mensajes.

Con respecto al tema sobre el cual versan las noticias falsas, el más recurrente en el conjunto de países estudiados fue el de los Falsos anuncios o acciones de Gobiernos, organizaciones o personajes públicos, relacionado con intenciones ideológicas [(des)acreditar fuentes o introducir debates anti o prosistema(s)] y, en segundo lugar, están los temas de salud, lo que coincide con los hallazgos reportados por Salaverría et al., (2020): supuestas curas, consejos y formas de contagio, temas que obtuvieron el primer puesto en Colombia, Bolivia y Perú. Esto muestra que la incertidumbre ante la pandemia y la falta de información científica veraz promueve falsas creencias en supuestas soluciones ancestrales o tradicionales, fomentando la peligrosa práctica de la 
automedicación para evitar el contagio. En el ámbito transnacional, este fue el tema de bulo más popular.

Al realizar el análisis de los seis países en conjunto, se encontró que en relación con ámbito predominaban los bulos sobre situaciones de orden nacional, seguidos de los que trataban aspectos internacionales. Sin embargo, las tablas comparativas mostraron que España, Bolivia y Perú los porcentajes significativamente elevados fueron los bulos de ámbito internacional, mientras que en Ecuador, Colombia y Argentina fueron los de procedencia nacional. Al mirar las características de las noticias falsas que se difundieron en varios países a la vez (transnacionales), se encontró que el hecho de que un bulo sea de ámbito internacional favorece que se difunda por varios países, posiblemente porque no se requiere demasiado esfuerzo para adaptarlo a los contextos nacionales particulares.

Se observó en los bulos transnacionales que aquellos mensajes similares entre sí circulan reforzando la desinformación involucrada, aunque cambie la pieza o el formato. Tal difusión es la que puede generar el efecto de verdad ilusoria (Pennycook et al., (2018) haciendo que las personas crean la información falsa contenida. Aun cuando no se efectuó la misma verificación acerca de la repetición de noticias en el conjunto de los 371 bulos analizados, se estima que la tendencia se repite, lo que podría derivar en una nueva investigación que explore la relación entre repetición frecuente del mensaje en distintos bulos y su aceptación como verdadero por parte de las personas.

Esta investigación mostró que un bajo porcentaje de noticias falsas llegó a los medios convencionales, lo cual podría significar que el periodismo de verificación (fact-checking journalism) es una práctica que sí ayuda a combatir el problema de las noticias falsas, sin que ello indique que su efecto sea representativo (Graves \& Glaisyer, 2012) pero, de alguna manera, logra alertar a los medios convencionales para no replicar noticias falsas.

Por otra parte, la intención detrás de la generación de noticias falsas fue principalmente de carácter ideológico, ya que a través de ellos se critica a la gestión de los gobernantes sobre la pandemia o, en ocasiones, se trata también de lograr respaldo a sus políticas. No obstante, la ideología también involucra aquellos casos en los que se trata de vender ideas antisistema, como la supuesta peligrosidad de las vacunas (abc.es, 2020) o la teoría de que las antenas 5G propagan la enfermedad, en cuyo discurso hay una intención desestabilizadora (ColombiaCheck, s. f.). En tales casos, hay que ponderar adecuadamente la idea principal del mensaje con que se pretende desinformar al público con el fin de poder clasificar correctamente la aparente intención que hay detrás de la misma. Si bien, con esta variable no se alcanza a ser exhaustivo, se espera aportar al análisis de la intencionalidad con que se generan noticias falsas.

Mientras que la teoría de la manipulación de la información (McCornack et al., 2014) aporta en la compresión sobre cómo se fabrica desinformación, las teorías de las cámaras de eco (Cardenal et al., 2019; Munson \& Resnick, 2010) y de burbujas de filtro (Pariser, 2011) aportan a la tendencia a compartir (des)información que coincide con los intereses y valores de los usuarios que las consumen. Por su parte, la teoría de la disonancia cognitiva (Festinger, 1957; Sindermann et al., 2020), complementa las anteriores al explicar la manera como se decide sobre lo que se comparte o no, bien sea (1) añadiendo (buscando) información consonante, (2) trivializando o infravalorando las actitudes consonantes de quien experimenta la disonancia, o (3) cambiando de postura o actitud hacia la (des)información que se consume.

Finalmente, conviene realizar un estudio complementario de corte cualitativo sobre las características discursivas de los bulos a fin de detallar las intencionalidades y las motivaciones de sus creadores, 
dada la marcada orientación a desestabilizar o generar pánico entre el público, como lo han reportado también otras investigaciones (Batasin, 2020; Karalis Noel, 2020). Este estudio aportaría en la delimitación de las categorías de intencionalidad propuestas en la presente investigación y podría ayudar tanto a detectar como a aclarar categorías de análisis aun inexploradas.

\section{Referencias}

abc.es. (2020, julio 17). Los antivacunas ponen en peligro la solución de la pandemia de COVID-19. abc. https://www.abc.es/salud/enfermedades/abci-antivacunas-ponen-peligro-solucion-pandemiacovid-19-202007171318_noticia.html

Allcott, H., \& Gentzkow, M. (2017). Social Media and Fake News in the 2016 Election. Journal of Economic Perspectives, 31(2), 211-236. https://doi.org/10.1257/jep.31.2.211

Alonso González, M. (2019). Fake News: Desinformación en la era de la sociedad de la información.

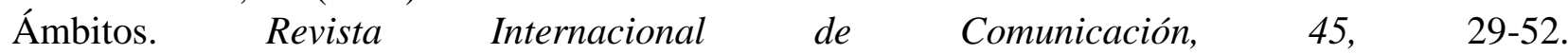
https://doi.org/10.12795/Ambitos.2019.i45.03

Aspray, W., \& Cortada, J. W. (2019). Recent Political Fact-Checking. En W. Aspray \& J. W. Cortada, From Urban Legends to Political Fact-Checking (pp. 107-133). Springer International Publishing. https://doi.org/10.1007/978-3-030-22952-8_5

Baron, S., \& Crootof, R. (2017). Fighting Fake News (p. 15). Floyd Abrams Institute for Freedom of Expression.

https://law.yale.edu/sites/default/files/area/center/isp/documents/fighting_fake_news__workshop_report.pdf

Batasin, S. J. A. (2020). Combating Xenophobia in the Covid-19 Pandemic: The Importance of Health Literacy. Inquiries Journal, http://www.inquiriesjournal.com/articles/1786/combating-xenophobia-in-the-covid-19-pandemicthe-importance-of-health-literacy

Berkowitz, D., \& Schwartz, D. A. (2016). Miley, CNN and The Onion: When fake news becomes realer than real. Journalism Practice, $10(1), \quad 17$. https://doi.org/10.1080/17512786.2015.1006933

Brennen, J. S., Simon, F. M., Howard, P. N., \& Nielsen, R. K. (2020). Types, Sources, and Claims of COVID-19 Misinformation (p. 13). Reuters Institute for the Study of Journalism. http://www.primaonline.it/wp-content/uploads/2020/04/COVID-19_reuters.pdf

Burkhardt, J. M. (2017). History of Fake News. Library Technology Reports, 53(8), 5-9.

Cardenal, A. S., Aguilar-Paredes, C., Cristancho, C., \& Majó-Vázquez, S. (2019). Echo-chambers in online news consumption: Evidence from survey and navigation data in Spain. European Journal of Communication, 34(4), 360-376. https://doi.org/10.1177/0267323119844409

ColombiaCheck. (s. f.). De nuevo, la tecnología 5G no es la causante del COVID-19. ColombiaCheck. Recuperado 11 de septiembre de 2020, de 
RLCS, Revista Latina de Comunicación Social, 78, 237-264

[Investigación] DOI: 10.4185/RLCS-2020-1476| ISSN 1138-5820| Año 2020

https://colombiacheck.com/index.php/chequeos/de-nuevo-la-tecnologia-5g-no-es-la-causante-del$\underline{\text { covid-19 }}$

Cortés, C., \& Isaza, L. (2017). Noticias falsas en Internet: La estrategia para combatir la desinformación (p. 26). Centro de Estudios en Libertad de Expresión y Acceso a la Información Universidad de Palermo. https://www.palermo.edu/cele/pdf/FakeNews.pdf

Country and Market Data. (2020). Digital News Report. http://www.digitalnewsreport.org/survey/2020/country-and-market-data-2020/

Elizabeth, J. (2014, mayo 20). Who are you calling a fact checker? American Press Institute. https://www.americanpressinstitute.org/fact-checking-project/fact-checker-definition/

Fallis, D. (2015). What Is Disinformation? Library Trends, 63(3), 401-426. https://doi.org/10.1353/lib.2015.0014

Farkas, J., \& Schou, J. (2018). Fake News as a Floating Signifier: Hegemony, Antagonism and the Politics of Falsehood. Javnost - The Public, 25(3), 298-314. https://doi.org/10.1080/13183222.2018.1463047

Festinger, L. (1957). A Theory of Cognitive Dissonance. Stanford University Press.

Giglietto, F., Iannelli, L., Valeriani, A., \& Rossi, L. (2019). 'Fake news' is the invention of a liar: How false information circulates within the hybrid news system. Current Sociology, 67(4), 625642. https://doi.org/10.1177/0011392119837536

Graves, L., \& Glaisyer, T. (2012, febrero 12). The Fact-Checking Universe in Spring 2012. New America. http://newamerica.org/oti/policy-papers/the-fact-checking-universe-in-spring-2012/

Han, B.-C. (2016). Sobre el poder. Herder Editorial.

Johnson, J. C., \& Stavru, A. (Eds.). (2019). 6. Pathos, physiognomy and ekphrasis from Aristotle to the Second Sophistic. En Visualizing the invisible with the human body (pp. 143-160). De Gruyter. https://doi.org/10.1515/9783110642698-007

Karalis Noel, T. (2020). Conflating culture with COVID-19: Xenophobic repercussions of a global pandemic. Social Sciences \& Humanities Open, 2(1), 100044. https://doi.org/10.1016/j.ssaho.2020.100044

Lazer, D. M. J., Baum, M. A., Benkler, Y., Berinsky, A. J., Greenhill, K. M., Menczer, F., Metzger, M. J., Nyhan, B., Pennycook, G., Rothschild, D., Schudson, M., Sloman, S. A., Sunstein, C. R., Thorson, E. A., Watts, D. J., \& Zittrain, J. L. (2018). The science of fake news. Science, 359(6380), 1094-1096. https://doi.org/10.1126/science.aao2998

McCornack, S. A., Morrison, K., Paik, J. E., Wisner, A. M., \& Zhu, X. (2014). Information Manipulation Theory 2: A Propositional Theory of Deceptive Discourse Production. Journal of Language and Social Psychology, 33(4), 348-377. https://doi.org/10.1177/0261927X14534656

Mitchell, A., Gottfried, J., Shearer, E., \& Lu, K. (2017, febrero 9). How Americans Encounter, Recall and Act Upon Digital News | Pew Research Center. Https://Www.Journalism.Org/. 
https://www.journalism.org/2017/02/09/how-americans-encounter-recall-and-act-upon-digitalnews/

Montero, I. (2005). Sistema de clasificación del método en los informes de investigación en Psicología. International Journal of Clinical and Health Psychology, 5(1), 115-127. http://www.redalyc.org/articulo.oa?id=33701007

Munson, S. A., \& Resnick, P. (2010). Presenting diverse political opinions: How and how much. Proceedings of the 28th International Conference on Human Factors in Computing Systems CHI'10, 1457. https://doi.org/10.1145/1753326.1753543

Newman, N. (s. f.). Reuters Institute Digital News Report 2020. 112.

Nielsen, R. K., \& Graves, L. (2017). «News you don't believe»: Audience perspectives on fake news. https://ora.ox.ac.uk/objects/uuid:6eff4d14-bc72-404d-b78a-4c2573459ab8

Pariser, E. (2011). The Filter Bubble: What The Internet Is Hiding From You. Penguin UK.

Parménides de Elea. (s. f.). Sobre la naturaleza. Fundación El Libro Total. Recuperado 20 de julio de 2020, de https://www.ellibrototal.com/ltotal/?t=1\&d=6631_6367_1_1_6631

Pennycook, G., Cannon, T. D., \& Rand, D. G. (2018). Prior exposure increases perceived accuracy of fake news. Journal of Experimental Psychology. General, 147(12), 1865-1880. https://doi.org/10.1037/xge0000465

Platón. (2003). Tres Dialogos Sobre Retorica—Comunicacion (A. S. Sáez, Trad.). UNAM.

Rainie, L., Anderson, J., \& Albright, J. (2017). The Future of Free Speech, Trolls, Anonymity, and Fake News Online (p. 82). Pew Research Center. http://www.elon.edu/docs/eweb/imagining/surveys/2016_survey/Pew\%20and\%20Elon\%20University $\% 20$ Trolls $\% 20$ Fake\%2 0News\%20Report\%20Future\%20of\%20Internet\%203.29.17.pdf

Rehm, G. (2018). An Infrastructure for Empowering Internet Users to Handle Fake News and Other Online Media Phenomena. En G. Rehm \& T. Declerck (Eds.), Language Technologies for the Challenges of the Digital Age (pp. 216-231). Springer International Publishing. https://doi.org/10.1007/978-3-319-73706-5_19

Salaverría, R., Buslón, N., López-Pan, F., León, B., López-Goñi, I., \& Erviti, M.-C. (2020). Desinformación en tiempos de pandemia: Tipología de los bulos sobre la Covid-19. El Profesional de la Información, 29(3), Article 3. https://doi.org/10.3145/epi.2020.may.15

Sindermann, C., Cooper, A., \& Montag, C. (2020). A short review on susceptibility to falling for fake political news. Current Opinion in Psychology, 36, 44-48. https://doi.org/10.1016/j.copsyc.2020.03.014

Tandoc, E. C., Lim, Z. W., \& Ling, R. (2018). Defining "Fake News": A typology of scholarly definitions. Digital Journalism, 6(2), 137-153. https://doi.org/10.1080/21670811.2017.1360143

Tanz, J. (2017, febrero 14). From Fake News to Disappearing Ad Revenue, Journalism Fights for Survival. wired.com. https://www.wired.com/2017/02/journalism-fights-survival-post-truth-era/ 
Vara Miguel, A., Amoedo, A., \& Negredo, S. (2020). Digital News Report España 2020. https://www.digitalnewsreport.es/

Vosoughi, S., Roy, D., \& Aral, S. (2018). The spread of true and false news online. Science, 359(6380), 1146-1151. https://doi.org/10.1126/science.aap9559

Wardle, C. (2017a, febrero 16). Fake news. It's complicated. First Draft. https://firstdraftnews.org:443/latest/fake-news-complicated/

Wardle, C. (2017b, marzo 14). Noticias falsas. Es complicado. First Draft News ES. https://es.firstdraftnews.org:443/2017/03/14/noticias-falsas-es-complicado/

\section{AUTORES:}

\section{Liliana María Gutiérrez-Coba}

Doctora en Ciencias de la Información por la Universidad del País Vasco (España), con énfasis en la investigación sobre temas relacionados con el periodismo, las tecnologías y la opinión pública. Es directora del Grupo de Investigación en Periodismo, GIP, de la Universidad de La Sabana, desde donde se ha dedicado a investigar sobre Calidad Informativa en el Periodismo, tanto analógico como digital. Investigadora Senior Minciencias.

lilianagc@unisabana.edu.co

\section{Índice H: 14}

Orcid ID: https://orcid.org/0000-0001-5532-8765

Google Scholar: https://scholar.google.com.co/citations?user=0mGtdeUAAAAJ\&hl=es

ResearchGate: https://www.researchgate.net/profile/Liliana_Gutierrez

\section{Patricia Coba-Gutiérrez.}

Licenciada en Español e Inglés de la Universidad del Tolima, Especialista en Enseñanza de la Literatura de la Universidad del Quindío. Magister en Educación de la Universidad del Tolima; Miembro del grupo de investigación Rastro Urbano; Investigadora junior reconocida por Minciencias (Colombia), Profesora Asociada de la Universidad de Ibagué.

patricia.coba@unibague.edu.co

\section{Índice H: 3}

Orcid ID: https://orcid.org/0000-0002-0713-6280

Google Scholar: https://scholar.google.com.mx/citations?hl=es\&user=J5pMK0kAAAAJ

ResearchGate: https://www.researchgate.net/profile/Patricia_Coba_Gutierrez

\section{Javier Andrés Gómez-Diaz}

Investigador psicosocial y estudiante de Doctorado en Psicología, docente de métodos cuantitativos y psicometría, reconocido por Minciencias (Colombia), miembro del grupo de investigación Psicología Básica y Aplicada para el Desarrollo Social.

javier.gomezd@uniminuto.edu

\section{Índice $\mathrm{H}$ : 4}

Orcid ID: https://orcid.org/0000-0002-2852-1970

Google Scholar: https://scholar.google.com.co/citations?hl=es\&user=86KEljsAAAAJ

ResearchGate: https://www.researchgate.net/profile/JAVIER_GOMEZ-DIAZ 


\section{Anexo 1}

Tabla de codificación de Variables

\begin{tabular}{|c|c|}
\hline Nombre de la Variable & Instrucciones de Codificación \\
\hline Código del bulo & Se escribe el código secuencialmente $1,2,3$, etc. \\
\hline Organización que verifica & $\begin{array}{l}\text { 1= Bolivia Verifica; } 2=\text { Maldita.es; } 3=\text { La Silla Vacía; } 4=\text { ColombiaCheck; } 5= \\
\text { Ecuador Chequea; } 6=\text { Newtral.es; } 7=\text { Chequeado; } 8=\text { OjoPúblico; } 9= \\
\text { larepublica.pe }\end{array}$ \\
\hline Título & Se escribe título de la noticia \\
\hline País en que circuló el bulo & $1=$ Colombia; $2=$ España; $3=$ Argentina; $4=$ Ecuador; $5=$ Bolivia; $6=$ Perú \\
\hline Tema & $\begin{array}{l}1=\text { Falsos anuncios o acciones del Gobierno, organizaciones o personajes } \\
\text { públicos; } 2=\text { Riesgo y formas de contagio; } 3=\text { Curas y consejos de salud; } 4= \\
\text { Ayudas económicas; } 5=\text { Teorías conspiratorias; } 6=\text { Situación de un país; } 7= \\
\text { Otros }\end{array}$ \\
\hline Ámbito & $1=$ Local; $2=$ Nacional; $3=$ Internacional \\
\hline Formato & $\begin{array}{l}\text { 1= Texto; } 2=\text { Audio; } 3=\text { Video; } 4=\text { Infográfico } ; 5=\text { Foto } ; 6=\text { imagen-texto } ;= \\
\text { imagen-audio; } 8=\text { imagen-video; } 9=\text { Texto-video } ; 10=\text { texto-audio }\end{array}$ \\
\hline Redes por las que circuló & $\begin{array}{l}1=\text { Whatsapp } ; 2=\text { Youtube } ; 3=\text { Facebook } ; 4=\text { Instagram } ; 5=\text { Twitter } ; 6=\text { Otros; } \\
7=\text { Todas las redes. }\end{array}$ \\
\hline Tipo de bulo & $\begin{array}{l}\text { 1= Sátira o parodia (en sentido de broma, no pretende hacer daño, pero } \\
\text { engaña); } 2=\text { Contenido engañoso (uso engañoso de la información para } \\
\text { incriminar a alguien o algo); } 3=\text { Contenido impostor (se suplanta a fuentes } \\
\text { genuinas) }\end{array}$ \\
\hline $\begin{array}{lll}\text { Técnica de engaño } \\
\text { utilizada }\end{array}$ & $\begin{array}{l}\text { 1= Conexión falsa (titulares, imágenes o leyendas no confirman el contenido); } \\
2=\text { Contexto falso (contenido genuino que se difunde con información de } \\
\text { contexto falsa); } 3=\text { Contenido manipulado (Información o imágenes genuinas } \\
\text { se manipulan para engañar); } 4=\text { Exageración (se basa en datos reales, pero } \\
\text { aumenta su alcance); } 5=\text { Contenido fabricado (contenido nuevo diseñado para } \\
\text { engañar y perjudicar) }\end{array}$ \\
\hline Intencionalidad & $\begin{array}{l}\text { 1= Clickbait u obtener más reproducciones; } 2=\text { Interés ideológico (desacreditar } \\
\text { o acreditar gobiernos o introducir debates antisistema o de respaldo al sistema); } \\
3=\text { Acciones delictivas (obtener datos personales o dinero); } 4=\text { Desestabilizar o } \\
\text { generar pánico. }\end{array}$ \\
\hline Fuente & $1=$ Anónima; $2=$ Real; $3=$ Ficticia; $4=$ Suplantada \\
\hline $\begin{array}{l}\text { Bulo reproducido en } \\
\text { medios de comunicación }\end{array}$ & $1=$ Sí; $2=$ No \\
\hline $\begin{array}{l}\text { Medios de comunicación } \\
\text { que publicaron la noticia } \\
\text { falsa }\end{array}$ & $\begin{array}{l}\text { 1= Impresos; } 2=\text { Televisión; } 3=\text { Radio; } 4=\text { Cibermedio; } 5=\text { Impreso y televisión; } \\
6=\text { Impresos y radio; } 7=\text { Impresos y cibermedios; } 8=\text { televisión y radio; } 9= \\
\text { televisión y cibermedios; } 10=\text { radio y cibermedios. }\end{array}$ \\
\hline Carácter transnacional & $\begin{array}{l}1=\text { La información falsa circuló en un solo país; } 2=\mathrm{La} \text { información falsa } \\
\text { circuló en varios países. }\end{array}$ \\
\hline $\begin{array}{l}\text { Países en los que se repitió } \\
\text { la información falsa }\end{array}$ & Escribir los países. \\
\hline $\begin{array}{l}\text { Cambios en las noticias } \\
\text { que se repiten }\end{array}$ & Escribir qué cambia en cada país en que se presenta la noticia falsa base. \\
\hline
\end{tabular}

